\title{
Genomics and proteomics of immune modulatory effects of a butanol fraction of echinacea purpurea in human dendritic cells Chien-Yu Wang1, Vanisree Staniforth ${ }^{1}$, Ming-Tsang Chiao1, Chia- Chung Hou ${ }^{1}$, Han-Ming Wu ${ }^{3}$, Kuo-Chen Yeh ${ }^{1}$, Chun-Houh Chen ${ }^{3}$, Pei- Ing Hwang ${ }^{3}$, Tuan-Nan Wen ${ }^{2}$, Lie-Fen Shyur*1 and Ning-Sun Yang*1
}

Address: ${ }^{1}$ Agricultural Biotechnology Research Center, Academia Sinica, Taipei 115, Taiwan, ${ }^{2}$ Institute of Plant and Microbial Biology, Academia Sinica, Taipei 115, Taiwan and ${ }^{3}$ Institute of Statistical Science, Academia Sinica, Taipei 115, Taiwan

Email: Chien-Yu Wang - sally@mail.biowell.com.tw; Vanisree Staniforth - vani@gate.sinica.edu.tw; Ming-Tsang Chiao - mtchiao@seed.net.tw; Chia-Chung Hou - cchon@gate.sinica.edu.tw; Han-Ming Wu - hmwu@mail.tku.edu.tw; Kuo-Chen Yeh - kcyeh@gate.sinica.edu.tw; ChunHouh Chen - cchen@stat.sinica.edu.tw; Pei-Ing Hwang - pihwang@gate.sinica.edu.tw; Tuan-Nan Wen - tnwen@sinica.edu.tw; Lie-

Fen Shyur* - lfshyur@ccvax.sinica.edu.tw; Ning-Sun Yang* - nsyang@gate.sinica.edu.tw

* Corresponding authors

Published: 13 October 2008

BMC Genomics 2008, 9:479 doi:10.1 I86/147|-2164-9-479
Received: I April 2008

Accepted: 13 October 2008

This article is available from: http://www.biomedcentral.com//47I-2/64/9/479

(c) 2008 Wang et al; licensee BioMed Central Ltd.

This is an Open Access article distributed under the terms of the Creative Commons Attribution License (http://creativecommons.org/licenses/by/2.0), which permits unrestricted use, distribution, and reproduction in any medium, provided the original work is properly cited.

\begin{abstract}
Background: Echinacea spp. extracts and the derived phytocompounds have been shown to induce specific immune cell activities and are popularly used as food supplements or nutraceuticals for immuno-modulatory functions. Dendritic cells (DCs), the most potent antigen presenting cells, play an important role in both innate and adaptive immunities. In this study, we investigated the specific and differential gene expression in human immature DCs (iDCs) in response to treatment with a butanol fraction containing defined bioactive phytocompounds extracted from stems and leaves of Echinacea purpurea, that we denoted $[\mathrm{BF} / \mathrm{S}+\mathrm{L} / \mathrm{Ep}]$.

Results: Affymetrix DNA microarray results showed significant up regulation of specific genes for cytokines (IL-8, IL-I $\beta$, and IL-I8) and chemokines (CXCL 2, CCL 5, and CCL 2) within $4 \mathrm{~h}$ after $[\mathrm{BF} / \mathrm{S}+\mathrm{L} / \mathrm{Ep}]$ treatment of iDCs. Bioinformatics analysis of genes expressed in $[\mathrm{BF} / \mathrm{S}+\mathrm{L} / \mathrm{Ep}]$-treated DCs revealed a key-signaling network involving a number of immune-modulatory molecules leading to the activation of a downstream molecule, adenylate cyclase 8. Proteomic analysis showed increased expression of antioxidant and cytoskeletal proteins after treatment with $[\mathrm{BF} / \mathrm{S}+\mathrm{L} / \mathrm{Ep}]$ and cichoric acid.

Conclusion: This study provides information on candidate target molecules and molecular signaling mechanisms for future systematic research into the immune-modulatory activities of an important traditional medicinal herb and its derived phytocompounds.
\end{abstract}

\section{Background}

Echinacea spp., commonly known as purple coneflower, is indigenous to North America. The use of Echinacea spp. as an herbal remedy originated in the medicinal culture of
North American Indians during the $17^{\text {th }}$ century and was later introduced to Europe. Its use became popular again in the early 1990s and continues today. Currently, Echinacea extracts from whole plant or specific tissue (e.g., root 
or aerial parts) are among the top-selling medicinal or food supplement products in the United States and Europe [1-3]. Recent studies have shown that treatment with specific Echinacea extracts activates macrophages, natural killer cells, or other immune cells [4-6]. Echinacea extracts have also been reported to stimulate the secretion of cytokines such as tumor necrosis factor-alpha, interferon, interleukin-1 and interleukin-6 [7-10]. In vivo studies have shown that treatment with Echinacea extracts can increase the number of white blood cells in the circulatory system [11], enhance phagocytosis [12], and trigger the alternate complementary pathway [13]. Echinacea extracts have been marketed as possible immune stimulators or enhancers worldwide. These phyto-extracts have been actively evaluated in various clinical studies as candidate therapeutics or preventive remedies for upper respiratory tract infections, common cold, urogenital infection and wound healing [14-19]. However, the results from various studies on the efficacy of Echinacea extracts for prevention of experimental colds or common cold have been controversial [16-20]. The most recent study, as a meta-analysis for evaluating the effect of Echinacea, addressed again on the potential use and problems of Echinacea as remedy for common cold/flu [20,21].

Dendritic cells (DCs) are involved in a spectrum of immune cell functions, including antigen-presentation and phagocytic activity, and play important roles in both innate and adaptive immunities [22]. DCs can capture and transfer molecular or cellular information from the body's outside or interface environment to cells of different immune systems. These cells are not only critical for the induction of primary immune responses but are also involved in the regulation of $\mathrm{T}$ cell-mediated immunity [22]. Recently, a series of studies developed DC-based immunotherapy or vaccine protocols designed to elicit specific immunity against certain cancers $[12,23,24]$. Echinacea plant extracts have been shown to have immunemodulatory effects $[3,11-13]$, and we recently reported on the possible use of Echinacea purpurea (Ep) phytocompounds as immune-modifiers for human DC activity [25]. Echinacea extracts have significant and specific modulatory effects on human DCs, but these effects are plant tissue-specific, the bioactivity varying greatly between root and shoot plus leaf $(\mathrm{S}+\mathrm{L})$ tissues. In this follow-up study, we further investigated in detail the effect of a partially purified and chemically defined Ep phytocompound mixture on human DCs.

Recent gene expression profiling in DCs have shown that DCs can actively process environmental signals and activate different transcriptional programs in response to distinct stimuli [26]. In this study, we used functional genomics to analyze changes in gene expression in human immature DCs in response to treatment with the butanol- partitioned fraction (BF) of the $\mathrm{S}+\mathrm{L}$ tissue extracts of $E$. purpurea $[\mathrm{BF} / \mathrm{S}+\mathrm{L} / \mathrm{Ep}]$ and cichoric acid (a major component of this fraction) through Affymetrix gene chip microarray analyses. High-resolution 2-D gel electrophoresis, MALDI-TOF mass spectrometry (MS), tandem MS-MS analysis, and bio-informatics database systems were subsequently employed for proteomics studies in parallel with the genomics studies. Results from these analyses and cell-based bioactivity-guide assays suggest that groups of differentially expressed genes, specific functional genes, and the associated molecular signaling networks can be employed as potential targets for future systematic studies of the response of human DC systems, as a response to traditional herbal medicine formulations or their derived phytocompounds.

\section{Results \\ Effect of [BF/S+L/Ep] extract on expression of cell surface markers in human iDCs}

Flow cytometry revealed that $[\mathrm{BF} / \mathrm{S}+\mathrm{L} / \mathrm{Ep}]$ enhanced the expression of CD83, a key marker for DC maturation in iDCs, as compared with vehicle $(0.1 \%$ DMSO) treatment (Figure 1) and the percentage of $\mathrm{CD}^{2} 3^{+}$expressing cells increased, from $20 \%$ to $45 \%$ with 10,50 and $100 \mu \mathrm{g} / \mathrm{ml}$ $[\mathrm{BF} / \mathrm{S}+\mathrm{L} / \mathrm{Ep}]$. However, treatment with the ethyl acetate (EA) fraction of the $\mathrm{S}+\mathrm{L}$ extract at 1,10 , or $50 \mu \mathrm{g} / \mathrm{ml} \mathrm{sig-}$ nificantly decreased the percentage of $\mathrm{CD} 83^{+}$expressing cells from $20 \%$ to $0 \%$ (Figure 1). The observed effects were not caused by cellular mechanisms related to cytotoxicity, since MTT assay results indicated that treatment with EA

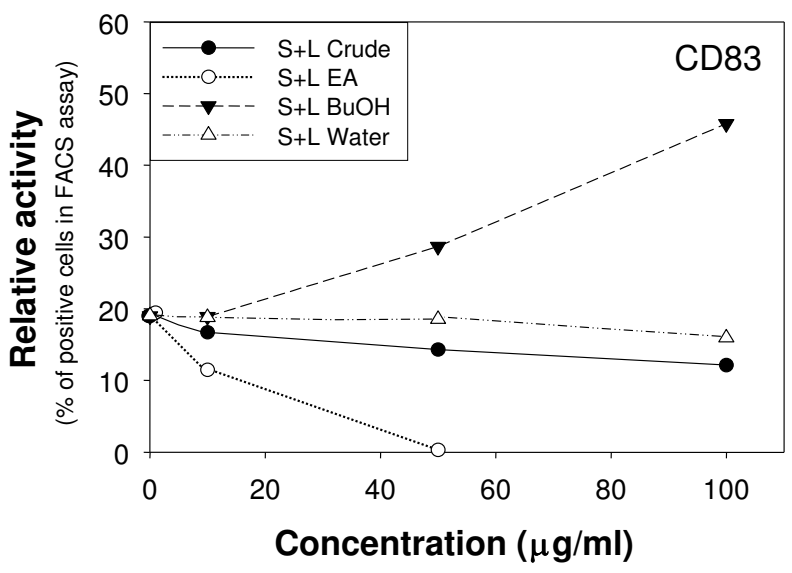

Figure I

Specific bioactivities of three subfractions of stem and leaf $(S+L)$ extracts of $E$. purpurea in human immature dendritic cells (iDC). iDCs were treated for $24 \mathrm{~h}$ with the $\mathrm{S}+\mathrm{L}$ tissue extracts and the derived ethyl acetate (EA), butanol $(\mathrm{BuOH})$, or water fractions. Test cells were subsequently analyzed for cell-surface marker CD83 expression by flow cytometry. 
( 1 to $50 \mu \mathrm{g} / \mathrm{ml}$ ) or [BF/S+L/Ep] (1 to $100 \mu \mathrm{g} / \mathrm{ml}$ ) showed $98 \%$ to $125 \%$ cell viability as compared to vehicle treatment (data not shown). Thus, the $[\mathrm{BF} / \mathrm{S}+\mathrm{L} / \mathrm{Ep}]$ fraction but not the EA fraction could enhance the maturation of iDCs. To reach this conclusion, it is essential for us to rule out the possibility that lipopolysaccharide (LPS), as a bacterial endotoxin contamination of the $[\mathrm{BF} / \mathrm{S}+\mathrm{L} / \mathrm{Ep}]$ extract preparations, might have contributed to the observed results in the present CD83 assay and the subsequent functional genomics and proteomics studies. By using a LAL assay (see Methods), we have obtained a firm negative results $(<0.125 \mathrm{EU} / \mathrm{ml})$ on the presence of a significant level of LPS in our $[\mathrm{BF} / \mathrm{S}+\mathrm{L} / \mathrm{Ep}]$ extract fraction. EchinaforceTM, a standardized commercial product from Swiss registered E. purpurea (L.) Moench fresh plant tincture, was reported to contain an endotoxin level of $<0.5$ $\mathrm{EU} / \mathrm{ml}$, and this tincture was used in a randomized double-blind clinical study [27]. In comparison, our plant extract fraction, $[\mathrm{BF} / \mathrm{S}+\mathrm{L} / \mathrm{Ep}]$, was detected to contain a considerably lower level of possible endotoxin contamination $(<0.125 \mathrm{EU} / \mathrm{ml})$. We therefore are confident that a LPS effect on various bioactivities can virtually be ruled out from our present studies.

\section{Compound identification and fingerprint analysis of the bioactive $[B F / S+L / E p]$ fraction}

The overall metabolite profile of [BF/S+L/Ep] of E. purpurea was analyzed using RP-HPLC, detected at $\mathrm{A}_{330}$ or $\mathrm{A}_{254}$ (Figure 2A). Seven phytocompounds (1-7) namely hypoxanthine (1), chlorogenic acid (2), caffeic acid (3), cichoric acid (4), quercetin 3-O-rhamnosyl-( $1 \rightarrow 6)$-galactoside (5), kaempferol 3-O-rhamnosyl-( $1 \rightarrow 6)$-galactoside (6), and rutin (7) were identified by a combination of chomatography on RP-18 silica gel, Sephadex gel, and C18 RP-HPLC. Structures were elucidated by ${ }^{1} \mathrm{H}$-nuclear magnetic resonance (NMR), ${ }^{13} \mathrm{C}-\mathrm{NMR}$ and MS, and confirmed with previous data [28-34]. LC/electrospray ionization-MS was further employed to establish the chemical fingerprints with two index compounds of $[\mathrm{BF} / \mathrm{S}+\mathrm{L} / \mathrm{Ep}]$. The RP-HPLC chromatogram detected at $330 \mathrm{~nm}$ of [BF/ $\mathrm{S}+\mathrm{L} / \mathrm{Ep}]$ was shown in Figure $2 \mathrm{~B}(\mathrm{a})$ and the mass spectra of the specific compounds were further characterized by using their pseudo molecular weight at $m / z 497[\mathrm{M}+\mathrm{Na}]^{+}$, $T_{R}=36.8 \mathrm{~min}$, compound 4, Figure 2B (b); and $m / z 611$ $[\mathrm{M}+\mathrm{H}]^{+}, \mathrm{T}_{R}=40.3 \mathrm{~min}$, compound 7, Figure 2B (c). These result demonstrate that compounds 4 and 7 in $[\mathrm{BF} / \mathrm{S}+\mathrm{L} /$ Ep] can be readily identified by comparing their corresponding peaks (retention time) and MS data.

The levels of cichoric acid (4) and rutin (7) were quantitatively determined for use as candidate index compounds for the $[\mathrm{BF} / \mathrm{S}+\mathrm{L} / \mathrm{Ep}]$ fraction. Standard calibration curves (peak area versus concentrations) prepared for cichoric acid and rutin ranged from 0.125 to $1 \mathrm{mg} / \mathrm{ml}$. Absorbance of the compounds at $330 \mathrm{~nm}$ varied linearly within this range. The amount of cichoric acid and rutin were determined as $8.4 \%(\mathrm{w} / \mathrm{w})$ and $22.3 \%(\mathrm{w} / \mathrm{w})$, respectively, of the dry weight of the $[\mathrm{BF} / \mathrm{S}+\mathrm{L} / \mathrm{Ep}]$ fraction. Together, the results show that this $[\mathrm{BF} / \mathrm{S}+\mathrm{L} / \mathrm{Ep}]$ phytocompound mixture was effectively standardized and defined with a specific metabolite profile containing several candidate index compounds (Figure 2). The standardized [BF/S+L/Ep] fraction was then systematically used in the following bioactivity assays to evaluate its immune regulatory effects in human iDCs.

\section{Affymetrix DNA microarray analysis of differential gene expression patterns in human iDCs in response to treatment with [BF/S+L/Ep] or cichoric acid}

For DNA microarray analysis, iDCs differentiated from primary monocytes in vitro were incubated with $[\mathrm{BF} / \mathrm{S}+\mathrm{L} /$ Ep] or cichoric acid for 4 or $24 \mathrm{~h}$ to characterize early- or late-responsive genes. A total of nine oligo-DNA chips were hybridized to determine the transcriptome profiles in human iDCs. The array data was normalized for identifying differentially expressed genes, clustering and annotation. We selected 382 genes for clustering by gap statistic analysis. Figure 3 shows a heat map of differential gene expression patterns and a plot of the resultant 6 possible gene clusters. The K-means clustering revealed that some genes exhibited a consistent response, for example with increased expression at both $4 \mathrm{~h}$ and $24 \mathrm{~h}$ after treatment with $[\mathrm{BF} / \mathrm{S}+\mathrm{L} / \mathrm{Ep}]$. Alternatively, some genes highly expressed at $4 \mathrm{~h}$ but not at $24 \mathrm{~h}$ after treatment, or at $24 \mathrm{~h}$ but not at $4 \mathrm{~h}$ post-treatment, and these may reflect other sets of specific and differential transient gene expression patterns.

Approximately 119 genes were up-regulated by $\geq 2$-fold change in expression at $4 \mathrm{~h}$ post-treatment with $[\mathrm{BF} / \mathrm{S}+\mathrm{L} /$ Ep], with 20 genes showing 11- to 31-fold change in expression (Table 1A). About 20 genes were down-regulated by $>2$-fold change in expression at $4 \mathrm{~h}$ post-treatment (Table 1A). Most notably, four up-regulated genes (CCL2 [MCP1], CCL5 [RANTES], NF- $\mathrm{BB}$ activator and IL8 ), and two down-regulated genes, IFN- $\alpha 16$ and leukocyte immunoglobulin-like receptor [LILRB3], are well known to be involved in various key immune-modulatory activities. Changes in expression noted after $24 \mathrm{~h}$ treatment are summarized in Table 1B. Treatment with cichoric acid, a key principle component of the $[\mathrm{BF} / \mathrm{S}+\mathrm{L} / \mathrm{Ep}]$ fraction, gave a different expression profile in iDCs. A total of 81 genes and 46 genes were up-regulated and down-regulated, respectively, with 2 -fold change in expression at $4 \mathrm{~h}$ posttreatment (data not shown). The top 20 up- or down-regulated genes, with 2.6- to 18.0-fold increase or 0.23- to 0.45 -fold decrease in expression at $4 \mathrm{~h}$ were chosen for further analysis (Table 2A). At $24 \mathrm{~h}$ after treatment, 79 genes were up-regulated and 81 down-regulated with $\geq 2$ fold change in expression (data not shown). The top 20 

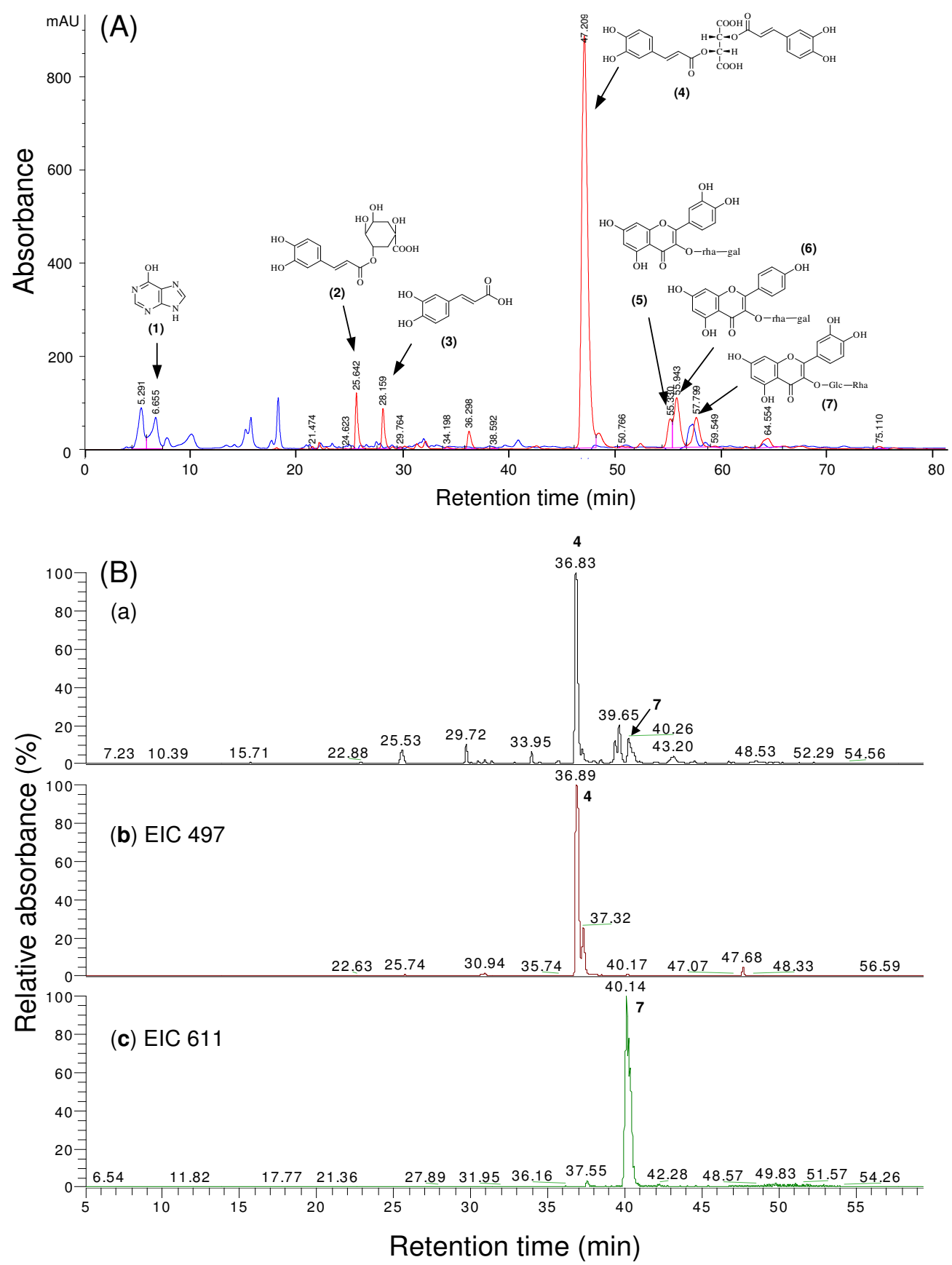

Figure 2

Chemical fingerprints and candidate index compounds identified in the [BF/S+L/Ep] fraction of $E$. purpurea. (A) Metabolite profile at 330 and $254 \mathrm{~nm}$ and the structures of compounds I-7 identified from [BF/S+L/Ep]. (B) RP-HPLC chromatogram of [BF/S+L/Ep] at $330 \mathrm{~nm}$ (a) analysis on ESI-MS to obtain $\mathrm{m} / \mathrm{z}$ ratios of (b) $\mathrm{m} / \mathrm{z} 497$, and (c) $\mathrm{m} / \mathrm{z} 6 \mathrm{II}$ for compounds 4 and 7 , respectively. 


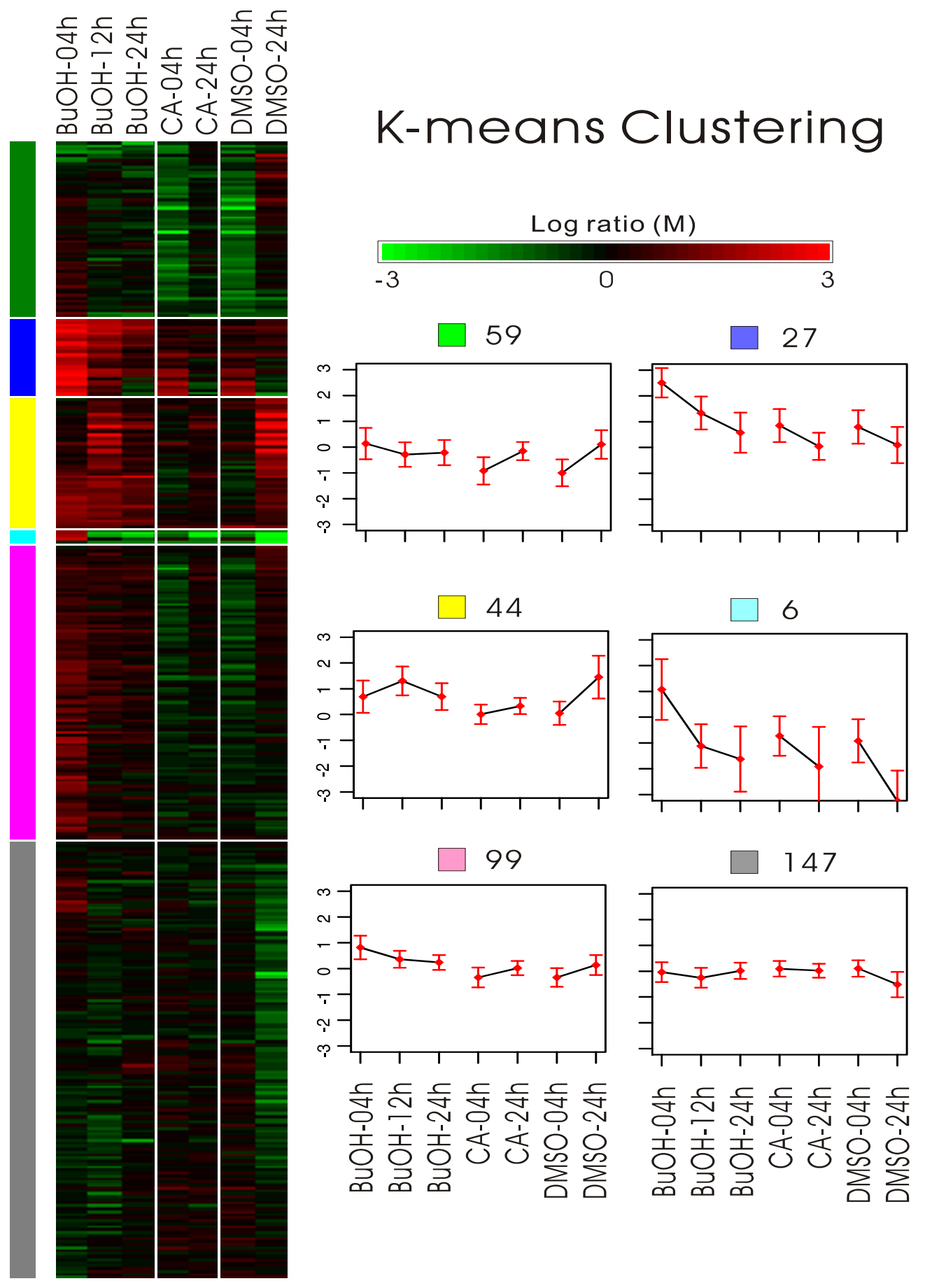

Figure 3

Comparative analysis of differential gene expression patterns in immature dendritic cells treated with [BF/ S+L/Ep] and specific phytocompounds by K-means clustering analyses. Analysis of test iDC samples (including vehicle control [+DMSO only]) involved comparing the treatment values with untreated values (i.e., zero hour-treated). The left panel shows the heat map of the resulting clustered gene expression. The number of genes involved and the mean profile for each cluster is in the right panel. The mean profile was superimposed with error bars showing \pm I standard error of the mean. 
Table I: Effect of [BF/S+L/Ep] on gene expression in human iDCs

\begin{tabular}{lcc}
\hline Gene Name & Fold Change & Treatment/Control \\
(From 3I to II-fold)
\end{tabular}

(A) Up-regulated at $4 \mathrm{~h}$ post-treatment

EH-domain containing I

chemokine ( $\mathrm{C}-\mathrm{C}$ motif) ligand 2

cryptochrome I (photolyase-like)

BCL-6 interacting corepressor

tumor necrosis factor receptor superfamily, member 4

Xenopus prevents mitotic catastrophe 2 homolog

basic transcription element binding protein I

Janus kinase 2 (a protein tyrosine kinase)

wingless-type MMTV integration site family, member $5 \mathrm{~A}$

discs, large (Drosophila) homolog I

RAB35, member RAS oncogene family

hypothetical protein DKFZp56400523

triple functional domain (PTPRF interacting)

zinc finger and BTB domain containing $I$

chemokine ( $\mathrm{C}-\mathrm{C}$ motif) ligand 5

TRAF family member-associated NF- $\mathrm{KB}$ activator

Interleukin 8

HSPCO34 protein

suppression of tumorigenicity

chemokine (C-X-C motif) ligand 2

Down-regulated at $4 \mathrm{~h}$ post-treatment

transducin (beta)-like 2 isoform I

decorin isoform a preproprotein

nucleolar protein family A, member 2

leukocyte immunoglobulin-like receptor

calpain 3 isoform a

interferon, alpha 16

chromosome 5 open reading frame 4

tripartite motif-containing 45

A kinase (PRKA) anchor protein 7 isoform alpha

carbonic anhydrase IV precursor

uncoupling protein 3 isoform UCP3L

NICE-4 protein

alpha 2 type $V$ collagen preproprotein

SWI/SNF-related matrix-associated actin-dependent regulator of chromatin a3

CD27-binding (Siva) protein isoform I

prostate derived STE20-like kinase PSK

stanniocalcin 2

arginine-glutamic acid dipeptide (RE) repeats

stimulated by retinoic acid gene 6

zinc finger protein 228

\begin{tabular}{|c|c|c|}
\hline EHDI & NM 006795 & 31.81 \\
\hline CCL2 & NM 002982 & 22.15 \\
\hline CRYI & NM 004075 & 21.65 \\
\hline BCOR & NM 017745 & 21.62 \\
\hline TNFRSF4 & NM 003327 & 19.10 \\
\hline XPMC2H & NM 020385 & 17.54 \\
\hline BTEBI & NM 001206 & 17.45 \\
\hline JAK2 & NM 004972 & 16.40 \\
\hline WNT5A & NM 003392 & 15.42 \\
\hline DLGI & NM 004087 & 15.22 \\
\hline RAB35 & NM 006861 & 14.79 \\
\hline DKFZP56400523 & ALI36619 & 14.17 \\
\hline TRIO & NM 007118 & 14.12 \\
\hline ZBTBI & NM 014950 & 13.75 \\
\hline CCL5 & NM 002985 & 13.62 \\
\hline TANK & BC003388 & 13.12 \\
\hline IL8 & NM 000584 & 12.16 \\
\hline LOC5I668 & NM 016126 & 11.37 \\
\hline ST7 & NM 013437 & 11.37 \\
\hline \multirow[t]{2}{*}{$\mathrm{CXCL2}$} & NM 002089 & 10.77 \\
\hline & & (From 0.49 to 0.47 -fold) \\
\hline TBL2 & NM 012453 & 0.50 \\
\hline $\mathrm{DCN}$ & NM 001920 & 0.50 \\
\hline NOLA2 & NM 017838 & 0.50 \\
\hline LILRB3 & NM_006864 & 0.50 \\
\hline CAPN3 & NM 000070 & 0.49 \\
\hline IFNAI 6 & $\overline{N M ~} 002173$ & 0.49 \\
\hline C5ORF4 & NM 016348 & 0.49 \\
\hline TRIM45 & NM 025188 & 0.49 \\
\hline AKAP7 & NM 004842 & 0.49 \\
\hline CA4 & NM 000717 & 0.49 \\
\hline UCP3 & NM 003356 & 0.49 \\
\hline NICE-4 & NM 014847 & 0.48 \\
\hline COL5A2 & $\overline{N M \quad 000393}$ & 0.48 \\
\hline SMARCA 3 & NM 00307I & 0.48 \\
\hline SIVA & NM 006427 & 0.48 \\
\hline PSK & NM 016151 & 0.48 \\
\hline STC2 & NM 003714 & 0.48 \\
\hline RERE & $\overline{N M ~} 012102$ & 0.48 \\
\hline FLJI254। & NM 022369 & 0.48 \\
\hline ZNF228 & NM 013380 & 0.48 \\
\hline
\end{tabular}

Fold Change

Common Name Accession No Treatment/Control (From 28 to 4.6-fold)

\section{Gene Name}

(B) Up-regulated at $24 \mathrm{~h}$ post-treatment

protein tyrosine phosphatase, non-receptor type 2 solute carrier family 26 , member 4

adaptor-related protein complex 4, sigma I subunit

zinc finger protein RINZF

calbindin I, 28kDa

chromosome 9 open reading frame 10

secreted frizzled-related protein I

cholinergic receptor, nicotinic, alpha polypeptide 5

chorea acanthocytosis

$\begin{array}{ccc}\text { PTPN2 } & \text { NM 002828 } & 28.77 \\ \text { SLC26A4 } & \underline{N M 000441} & 25.07 \\ \text { AP4SI } & \underline{N M 007077} & 23.91 \\ \text { RINZF } & \underline{N M 023929} & 15.88 \\ \text { CALBI } & \underline{N M 004929} & 15.57 \\ \text { C9ORFI0 } & \underline{A F 214738} & 12.75 \\ \text { SFRPI } & \underline{N M 003012} & 10.17 \\ \text { CHRNA5 } & \underline{N M 000745} & 9.95 \\ \text { CHAC } & \underline{A B 023203} & 9.91\end{array}$

Page 6 of 20

(page number not for citation purposes) 
Table I: Effect of [BF/S+L/Ep] on gene expression in human iDCs (Continued)

\begin{tabular}{|c|c|c|c|}
\hline WAP four-disulfide core domain 8 & WFDC8 & $\underline{A L|3357|}$ & 8.68 \\
\hline tripartite motif-containing 45 & TRIM45 & NM 025188 & 8.34 \\
\hline matrix metalloproteinase 2 & MMP2 & NM 004530 & 6.73 \\
\hline hookl protein & HOOKI & NM 015888 & 6.52 \\
\hline epidermal growth factor receptor pathway substrate 8-related protein I & EPS8RI & Al343292 & 6.23 \\
\hline zinc finger protein (ZFD25) & ZFD25 & NM 016220 & 5.27 \\
\hline SUMO-I-specific protease & SUSPI & NM 01557I & 5.02 \\
\hline nuclear respiratory factor I & NRFI & NM 005011 & 4.97 \\
\hline phosphoribosyl pyrophosphate amidotransferase & PPAT & NM 002703 & 4.86 \\
\hline pleckstrin homology-like domain, family A, member I & PHLDAI & NM 007350 & 4.79 \\
\hline vascular Rab-GAP/TBC-containing & VRP & NM 000993 & 4.61 \\
\hline Down-regulated at $24 \mathrm{~h}$ post-treatment & & & (From 0.03 to 0.24 -fold) \\
\hline Chromosome I open reading fram 29 & CIORF29 & NM 006820 & 0.04 \\
\hline protein (peptidyl-prolyl cis/trans isomerase) NIMA-interacting I & PINI & NM 006221 & 0.04 \\
\hline myxovirus resistance protein I & $M \times 1$ & NM 002462 & 0.09 \\
\hline sialoadhesin precursor & SN & NM 023068 & 0.10 \\
\hline interferon-induced protein with tetratricopeptide repeats I & IFITI & NM 001548 & 0.12 \\
\hline axonemal dynein heavy chain 7 & DNAH7 & NM 018897 & 0.13 \\
\hline ubiquitin specific protease 18 & USPI8 & NM 017414 & 0.14 \\
\hline regulator of G-protein signaling 12 & RGSI2 & NM 002926 & 0.14 \\
\hline interferon-induced, hepatitis C-associated microtubular aggregate & IFI44 & NM 006417 & 0.16 \\
\hline secreted protein of unknown function & SPUF & NM 013349 & 0.17 \\
\hline vacuolar protein sorting $4 \mathrm{I}$ (yeast homolog) isoform I & VPS4I & NM 014396 & 0.18 \\
\hline SPI 40 nuclear body protein & SPI40 & NM 007237 & 0.19 \\
\hline interferon, alpha-inducible protein & GIP2 & NM 005101 & 0.19 \\
\hline interferon-induced protein with tetratricopeptide repeats 4 & IFIT4 & NM 001549 & 0.21 \\
\hline small inducible cytokine BII precursor & CXCLII & NM 005409 & 0.29 \\
\hline phospholipid scramblase I & PLSCRI & NM 021105 & 0.22 \\
\hline viperin & CIG5 & NM 080657 & 0.22 \\
\hline muscle-specific beta I integrin binding protein & MIBP & NM 170678 & 0.23 \\
\hline translation initiation factor IF2 & IF2 & NM 015904 & 0.25 \\
\hline serine (or cysteine) proteinase inhibitor, clade A, member I & SERPINAI & NM_000295 & 0.25 \\
\hline
\end{tabular}

Top 20 genes up- or down-regulated in human immature DCs in response to treatment with (BF/S+L/Ep) fraction of Echinacea purpurea for $4 \mathrm{~h}(\mathrm{~A})$ or $24 \mathrm{~h}(\mathrm{~B})$ by fold change in expression.

up- or down-regulated genes, with 5.36- to 18.9-fold increase or 0.13 - to 0.37 -fold decrease in expression at 24 $\mathrm{h}$ were chosen for further evaluation (Table 2B). As shown in Table 3, among the groups of genes up- or down-regulated by cichoric acid versus [BF/S+L/Ep] treatment for 24 $\mathrm{h}$, an overlapping expression pattern was observed for 31 genes.

\section{Putative signaling networks/pathways involved in the modulatory effect of [BF/S+L/EP] on iDCs}

To identify the possible putative signal transduction pathways, we analyzed, for $4 \mathrm{hr}$ and $24 \mathrm{hr}$ treatments, the top 20 up-regulated genes in human iDCs in response to treatment with $[\mathrm{BF} / \mathrm{S}+\mathrm{L} / \mathrm{Ep}]$ using TRANSPATH soft ware. Signal transduction pathways involving the MCP-1, IL-8, CCL5, JAK2 and TRIO genes with $\geq 5$-fold change in expression on treatment (Table 1A) was identified. Signaling pathway networking and gene function analyses led to the hypothesis that treatment of iDC with $[\mathrm{BF} / \mathrm{S}+\mathrm{L} / \mathrm{Ep}]$ may activate the cyclic AMP and PKC pathways leading to the regulation of a key down stream molecule, adenylate cyclase 8 (AC8), in a $\mathrm{Ca}^{2+}$ dependent manner (Figure 4).

\section{Construction of proteome maps and identification of} differentially expressed proteins in human iDCs

Treatment of iDCs with $75 \mu \mathrm{g} / \mathrm{ml}[\mathrm{BF} / \mathrm{S}+\mathrm{L} / \mathrm{Ep}]$ or $50 \mu \mathrm{g} /$ $\mathrm{ml}$ cichoric acid resulted in differential expression of 43 proteins (Figures 5 and Table 4 ) identified by MALDITOF-MS. These 43 proteins were further categorized by function with use of the Swiss-Prot database. Most of the proteins responding to $[\mathrm{BF} / \mathrm{S}+\mathrm{L} / \mathrm{Ep}](30.2 \%)$ were cell growth- or maintenance-related proteins (Figure 6); these included structural and cytoskeleton proteins such as macrophage-capping protein, cofilin, profilin, F-actin capping protein $\beta$ subunit, and laminin A/C (Table 4). Other major classes were energy pathway-related proteins or metabolic enzymes $(26.4 \%)$, proteins involved in protein metabolism or degradation (18.9\%), and ion channel/transport proteins (13.2\%). A small number were related to signal transduction and cell communication $(5.7 \%)$, and others were associated with the regulation of nucleotides and nucleic acid metabolism (5.7\%). Some proteins of interest include oxidative stress-related proteins (superoxide dismutases [ $\mathrm{Mn}, \mathrm{Cu}$ and $\mathrm{Zn}]$, catalase and peroxiredoxin 6) and cytoskeleton related proteins (gelsolin, macrophage capping protein, actin related pro- 
Table 2: Effect of cichoric acid on gene expression in human iDCs

$\begin{array}{lcc}\text { Gene Name } & \begin{array}{c}\text { Fold Change } \\ \text { Treatment/Control } \\ \text { (From 18 to 2.6-fold) }\end{array}\end{array}$

\section{(A) Up-regulated at $4 \mathrm{~h}$ post-treatment}

discs, large (Drosophila) homolog I

pre-B-cell leukemia transcription factor 2

inhibitor of DNA binding 4, dominant negative helix-loop-helix protein contactin associated protein-like 2

DEAD/H (Asp-Glu-Ala-Asp/His) box polypeptide 6 (RNA helicase, $54 \mathrm{kDa}$ )

guanine nucleotide binding protein ( $\mathrm{G}$ protein), alpha inhibiting activity polypeptide I

tropomodulin 3 (ubiquitous)

tissue factor pathway inhibitor (lipoprotein-associated coagulation inhibitor)

tolloid-like I

RAB3 GTPase-activating protein

histone I, H2al

solute carrier family 4 , sodium bicarbonate cotransporter, member 7

fibulin I

cytochrome P450, family 2 , subfamily C, polypeptide 8

peptidyl-prolyl isomerase $\mathrm{G}$ (cyclophilin G)

Nijmegen breakage syndrome I (nibrin)

NADH dehydrogenase (ubiquinone) I beta subcomplex, 2, $8 \mathrm{kDa}$

cytosolic ovarian carcinoma antigen I

zinc finger protein 305

platelet-activating factor acetylhydrolase, isoform lb, beta subunit $30 \mathrm{kDa}$

Down-regulated at $4 \mathrm{~h}$ post-treatment

glycerol kinase

SMC4 structural maintenance of chromosomes 4-like I (yeast)

ATPase, $\mathrm{Ca}^{+2}$ transporting, type $2 \mathrm{C}$, member I

megakaryocyte-associated tyrosine kinase

ubiquitin specific protease 24

SEC24 related gene family, member D (S. cerevisiae)

talin I

methionyl aminopeptidase 2

protein kinase, cAMP-dependent, regulatory, type II, beta endothelial differentiation, G-protein-coupled receptor, 2 integrin, beta 8

uridine monophosphate synthetase

ribosomal protein $\mathrm{LI} 3$

DNA cross-link repair IB

chloride channel, calcium activated, family member 2

caspase 2, apoptosis-related cysteine protease

apoptotic chromatin condensation inducer in the nucleus

peptidoglycan recognition protein-l-beta precursor

\begin{tabular}{|c|c|c|}
\hline DLGI & NM 004087 & 18.24 \\
\hline PBX2 & NM 002586 & 6.45 \\
\hline ID4 & NM 001546 & 4.22 \\
\hline CNTNAP2 & NM 014141 & 4.00 \\
\hline DDX6 & NM 004397 & 3.74 \\
\hline GNAII & NM 002069 & 3.66 \\
\hline TMOD3 & NM 014547 & 3.60 \\
\hline TFPI & NM_006287 & 3.13 \\
\hline TLLI & NM 012263 & 3.09 \\
\hline RAB3GAP & XM_040048 & 3.0 \\
\hline HISTIH2AL & NM 003511 & 3.07 \\
\hline SLC4A7 & NM 003615 & 3.00 \\
\hline FBLNI & NM_006486 & 2.97 \\
\hline CYP2C8 & NM 030878 & 2.8 \\
\hline PPIG & NM 004792 & 2.80 \\
\hline NBSI & AK00I0I7 & 2.76 \\
\hline NDUFB2 & NM 004546 & 2.71 \\
\hline COVAI & NM 006375 & 2.6 \\
\hline ZNF305 & NM 014724 & 2.6 \\
\hline PAFAHIB2 & NM 002572 & 2.6 \\
\hline
\end{tabular}

(From 0.23 to $\mathbf{0 . 4 5}$-fold)

$\begin{array}{lll}\text { GK } & \text { NM } 000167 & 0.23\end{array}$

SMC4LI $\quad \frac{A L I 36877}{A B 037768} \quad 0.31$

$\begin{array}{lll}\text { ATP2CI } & \text { AB037768 } & 0.36\end{array}$

$\begin{array}{lll}\text { MATK NM } 002378 & 0.37\end{array}$

$\begin{array}{lll}\text { USP24 } & \text { XM } 165973 & 0.37\end{array}$

SEC24D NM $014822 \quad 0.38$

TLNI NM 006289

$\begin{array}{lll}\text { METAP2 } & \text { NM } 006838 & 0.39\end{array}$

$\begin{array}{lll}\text { PRKAR2B } & \text { NM } 002736 & 0.42\end{array}$

EDG2 NM 00140I $\quad 0.42$

ITGB8 $\quad$ NM 002214 $\quad 0.42$

$\begin{array}{lll}\text { UMPS } & \text { NM } 000373 & 0.42\end{array}$

$\begin{array}{lll}\text { RPLI3 } & \text { AA789278 } & 0.43\end{array}$

DCLREIB NM $022836 \quad 0.43$

$\begin{array}{lll}\text { CLCA2 NM } 006536 & 0.43\end{array}$

$\begin{array}{lll}\text { CASP2 } & \text { NM } 032982 & 0.44\end{array}$

ACINUS $\quad$ NM $014977 \quad 0.45$

PGLYRPIBETA NM $020393 \quad 0.45$

\section{Gene Name}

Common Name Accession No
Fold Change

Treatment/Control (From 18.9 to 5.4-fold)

(B) Up-regulated at $24 \mathrm{~h}$ post-treatment

Zinc finger protein 229

adaptor-related protein complex 4 , sigma I subunit

chromosome 8 open reading frame 17

DKFZP566K023 protein

glycine receptor, alpha I

frizzled homolog 3 (Drosophila)

secreted frizzled-related protein I

chorea acanthocytosis

actin, alpha, cardiac muscle

tripartite motif-containing 45

phosphodiesterase 4D, cAMP-specific

$\begin{array}{ccc}\text { ZNF228 } & \underline{A C 084239} & 18.93 \\ \text { AP4SI } & \underline{N M 007077} & 14.10 \\ \text { C8ORFI7 } & \underline{N M 020237} & 12.13 \\ \text { DKFZP566K023 } & \underline{N M 015485} & 11.07 \\ \text { GLRAI } & \underline{N M 000171} & 10.81 \\ \text { FZD3 } & \underline{N M 017412} & 10.31 \\ \text { SFRPI } & \underline{N M 003012} & 10.11 \\ \text { CHAC } & \underline{A B 023203} & 9.56 \\ \text { ACTC } & \underline{N M 005159} & 9.51 \\ \text { TRIM45 } & \underline{N M 025188} & 8.26 \\ \text { PDE4D } & \underline{A F 012073} & 8.23\end{array}$


Table 2: Effect of cichoric acid on gene expression in human iDCs (Continued)

\begin{tabular}{|c|c|c|c|}
\hline v-Ki-ras2 Kirsten rat sarcoma 2 viral oncogene homolog & KRAS2 & NM 004985 & 7.79 \\
\hline absent in melanoma I-like & AIMIL & NM 017977 & 6.79 \\
\hline protein phosphatase 2 , regulatory subunit $\mathrm{B}$, beta isoform & PPP2R2B & NM 004576 & 6.75 \\
\hline integral membrane protein $2 \mathrm{~A}$ & ITM2A & AL021786 & 6.43 \\
\hline cannabinoid receptor I (brain) & CNRI & $\underline{U} 73304$ & 6.09 \\
\hline cholinergic receptor, nicotinic, alpha polypeptide 5 & CHRNA5 & NM 000745 & 6.02 \\
\hline SMC5 structural maintenance of chromosomes 5-like I (yeast) & SMC5LI & $\overline{N M 015110}$ & 5.78 \\
\hline protein kinase, cAMP-dependent, regulatory, type I, beta & PRKARIB & $\underline{\text { AL833563 }}$ & 5.77 \\
\hline ATP-binding cassette, sub-family $A(A B C I)$, member I & $A B C A I$ & AF285167 & 5.36 \\
\hline Down-regulated at $24 \mathrm{~h}$ post-treatment & & & (From 0.13 to 0.37 -fold) \\
\hline interferon-inducible protein p78 (mouse) & MXI & NM 002462 & 0.13 \\
\hline interferon-induced protein 44 & IFI44 & NM 006417 & 0.16 \\
\hline interferon, alpha-inducible protein (clone IFI-I5K) & GIP2 & NM 005101 & 0.20 \\
\hline protein kinase, interferon-inducible double stranded RNA dependent & PRKR & NM 002759 & 0.21 \\
\hline 2'-5'-oligoadenylate synthetase $2,69 / 71 \mathrm{kDa}$ & OAS2 & NM 016817 & 0.24 \\
\hline BCL2-like II (apoptosis facilitator) & BCL2LII & NM 006538 & 0.28 \\
\hline methionyl aminopeptidase 2 & METAP2 & NM 006838 & 0.28 \\
\hline signal transducer and activator of transcription I (9l kDa) & STATI & NM 007315 & 0.29 \\
\hline myxovirus (influenza virus) resistance 2 (mouse) & $M \times 2$ & NM 002463 & 0.30 \\
\hline SPIIO nuclear body protein & SPIIO & AF280094 & 0.30 \\
\hline sialoadhesin & SN & NM 023068 & 0.30 \\
\hline mitochondrial ribosomal protein $\mathrm{SI} 4$ & MRPSI 4 & NM 022100 & 0.31 \\
\hline similar to S. cerevisiae SSM4 & TEB4 & NM 005885 & 0.31 \\
\hline XIAP associated factor-I & HSXIAPAFI & NM 017523 & 0.33 \\
\hline SPIIO nuclear body protein & SPIIO & NM 004509 & 0.35 \\
\hline retinitis pigmentosa 2 (X-linked recessive) & RP2 & NM 006915 & 0.36 \\
\hline zinc finger protein $83(\mathrm{HPFI})$ & ZNF83 & NM 018300 & 0.36 \\
\hline zinc finger antiviral protein & ZAP & NM 020119 & 0.36 \\
\hline TIAI cytotoxic granule-associated RNA binding protein & TIAI & NM 022173 & 0.38 \\
\hline RAN binding protein 9 & RANBP9 & NM 005493 & 0.38 \\
\hline
\end{tabular}

Top 20 genes up- or down-regulated in human immature DCs in response to treatment with cichoric acid (50 g/ml) of Echinacea purpurea for $4 \mathrm{~h}$ (A) by fold change in expression.

tein 3, coronin-1C, beta adducin, vimentin, WD-repeat protein 1, T-complex protein 1 epsilon subunit, T-complex protein 1 - beta subunit, cofilin, F-actin capping protein beta subunit 2, actin-related protein 2/3 complex subunit 2, profilin-1). These specific proteins may warrant further evaluation because of their apparent roles in modulation of DC maturation and function.

\section{Confirmation of up- or down-regulation of specific proteins}

Western blot analysis was conducted to confirm some of the up-regulated proteins observed from proteomic analysis. The expression of Mn-SOD (SOD2) was increased 2.65- to 1.99-fold with [BF/S+L/Ep] and 2.35- and 1.67fold with cichoric acid treatment at 12 and $24 \mathrm{~h}$, respectively, as compared with vehicle controls, which is consistent with results from 2-D gel electrophoresis (Figure 7, Table 4). The levels of cofilin determined by 2-D gel electrophoresis (Figure 8A) were slightly decreased, by 0.75 and 0.84 -fold, with $[\mathrm{BF} / \mathrm{S}+\mathrm{L} / \mathrm{Ep}]$ and greatly decreased, by 0.09 - and 0.42 -fold, with cichoric acid treatment at 12 or $24 \mathrm{~h}$, respectively. Interestingly, confirmation by Western blot analysis revealed only a 0.5 - and 0.32 -fold decrease in cofilin level at 12 and $24 \mathrm{~h}$ with cichoric acid treatment (Figure 8B). Both assay systems revealed reduced effect of
[BF/S+L/Ep] on cofilin expression in iDCs (0.75- and 0.84 -fold, respectively) (Figure $8 \mathrm{~A}$ Vs $8 \mathrm{~B}$ ). Nevertheless, these results confirmed our finding that the expression of cofilin in iDCs can be substantially reduced by treatment with cichoric acid and may be slightly inhibited by [BF/ $\mathrm{S}+\mathrm{L} / \mathrm{Ep}]$. Rutin, another major index component of the $[\mathrm{BF} / \mathrm{S}+\mathrm{L} / \mathrm{Ep}]$, effectively inhibited the expression of cofilin, by 0.4 - and 0.6 -fold at 12 and $24 \mathrm{~h}$, respectively, in iDCs (Figure 8B). Treatment with $100 \mathrm{ng} / \mathrm{ml}$ lipopolysaccharide (LPS, used as a positive control) conferred an approximately 0.5 - to 0.4 -fold decrease in cofilin expression as compared to controls (Figure 8B).

\section{Discussion}

Results of some clinical studies are controversial about the effects of the traditional herbal medicine Echinacea extracts [14-19], even though recent studies seemed to provide some support for its possible beneficial effects for treatment of the common cold $[20,21]$. In addition, studies from animal experiments have shown that alkamides form Echinacea extracts may confer immune-modulatory activities [35,36]. Among these different observations, we believe it is important to evaluate systematically the specific and multiple effects of Echinacea phytocompounds on human immune cells, at the cellular and molecular 
Table 3: Genes showing overlapping up- or down-regulation in iDCs after treatment with [BF/S+L/Ep] or cichoric acid

\begin{tabular}{|c|c|c|c|}
\hline Genes up-regulated & Genebank & $\begin{array}{l}\text { Fold Change in Treatment with [BF/ } \\
\text { S+L/Ep] (From } 23.9 \text { to } 2.7 \text {-fold) }\end{array}$ & $\begin{array}{l}\text { Fold Change in Treatment with } \\
\text { Cichoric Acid (From } 14 \text { to } 3.1 \text {-fold) }\end{array}$ \\
\hline adaptor-related protein complex 4 & NM 007077 & 23.91 & 14.10 \\
\hline secreted frizzled-related protein I & NM 003012 & 10.17 & 10.11 \\
\hline cholinergic receptor & NM 000745 & 9.95 & 6.02 \\
\hline chorea acanthocytosis & $\underline{\mathrm{AB} 023203}$ & 9.91 & 9.56 \\
\hline tripartite motif-containing 45 & NM 025188 & 8.34 & 8.26 \\
\hline zinc finger protein (ZFD25) & NM 016220 & 5.27 & 5.35 \\
\hline SUMO-I-specific protease & NM 01557I & 5.02 & 4.56 \\
\hline nuclear respiratory factor I & NM 005011 & 4.97 & 3.39 \\
\hline pleckstrin homology-like domain & NM 007350 & 4.79 & 3.36 \\
\hline protein phosphatase 2 & NM 004576 & 4.56 & 6.75 \\
\hline chromosome 19 open reading frame 2 & NM 003796 & 3.91 & 3.27 \\
\hline $\begin{array}{l}\text { SMC5 structural maintenance of } \\
\text { chromosomes 5-like I (yeast) }\end{array}$ & NM 015110 & 3.87 & 5.78 \\
\hline $\begin{array}{l}\text { myeloid/lymphoid or mixed-lineage } \\
\text { leukemia }\end{array}$ & NM 00464I & 3.70 & 5.34 \\
\hline $\begin{array}{l}\text { aryl hydrocarbon receptor interacting } \\
\text { protein-like I }\end{array}$ & $\underline{N M \quad 014336}$ & 3.60 & 3.70 \\
\hline left-right determination, factor B & NM 020997 & 3.53 & 4.14 \\
\hline ATP-binding cassette, sub-family A & NM 005502 & 3.35 & 5.36 \\
\hline RBPI-like protein & NM 016374 & 3.07 & 3.26 \\
\hline solute carrier family 26, member 10 & NM 133489 & 2.89 & 3.05 \\
\hline insulin induced gene I & NM 005542 & 2.87 & 3.12 \\
\hline ceroid-lipofuscinosis, neuronal 8 & NM 018941 & 2.72 & 3.10 \\
\hline Genes down-regulated & $\overline{\text { Gene bank }}$ & (From 0.08 to 0.38 -fold) & (From 0.13 to 0.4 -fold) \\
\hline $\begin{array}{l}\text { Interferon-inducible protein p78 } \\
\text { (mouse) }\end{array}$ & NM 002462 & 0.09 & 0.13 \\
\hline Interferon-inducible protein 44 & NM 006417 & 0.16 & 0.16 \\
\hline $\begin{array}{l}\text { Interferon, alpha-inducible protein } \\
\text { (clone IFI-I5K) }\end{array}$ & NM 005101 & 0.19 & 0.20 \\
\hline Mitochondrial ribosomal protein SI4 & NM 022100 & 0.27 & 0.31 \\
\hline $\begin{array}{l}\text { 2'-5'-oligoadanylate synthetase } 2,69 / \\
71 \mathrm{kDa}\end{array}$ & NM 016817 & 0.27 & 0.24 \\
\hline $\begin{array}{l}\text { Myxovirus (influenza virus) resistance } \\
2 \text { (mouse) }\end{array}$ & NM 002463 & 0.29 & 0.30 \\
\hline XIAP associated factor-I & $\underline{N M \quad 017523}$ & 0.30 & 0.33 \\
\hline SPII0 nuclear body protein & NM 080424 & 0.33 & 0.35 \\
\hline $\begin{array}{l}\text { Signal transducer and activator of } \\
\text { transcription I, }(91 \mathrm{kDa})\end{array}$ & NM 007315 & 0.33 & 0.29 \\
\hline zinc finger antiviral protein & NM 020119 & 0.34 & 0.36 \\
\hline Solute carrier family 35 & NM 012243 & 0.36 & 0.38 \\
\hline
\end{tabular}

Human immature DCs were treated for $24 \mathrm{~h}$ with test samples and assayed for differential gene expression.

levels. Previously, we reported that un-fractionated, crude extracts of E. purpurea plant tissues could affect specific cell-surface markers of human DCs [25], which suggests the potential of using human DCs as an experimental system for in-depth study of the effect of Echinacea phytocompounds on important human immune cell systems. In the current study, we evaluated and characterized the possible immune-modulatory effect(s) of phytocompounds from E. purpurea, as an organic solvent-fractionated phytocompound mixture or a single major component (cichoric acid), on human DCs. Using transcriptome and proteome experimental approaches, we analyzed the global and differential gene expression pat- terns at the mRNA and protein levels in human monocyte-derived iDCs treated with test phytocompounds.

Previous studies have demonstrated that DCs play important roles in initiating and regulating innate as well as adaptive immunities [22]. Under normal conditions, DCs are present in most tissues in a relatively immature state, but with inflammation, irritation or danger signals from foreign antigens or environment, iDCs undergo rapid changes and initiate a cascade of activities to defend the body system. The phenotypic and functional characteristics of DCs are intimately and dynamically linked to their stage of differentiation and maturation [37]. Human DCs 


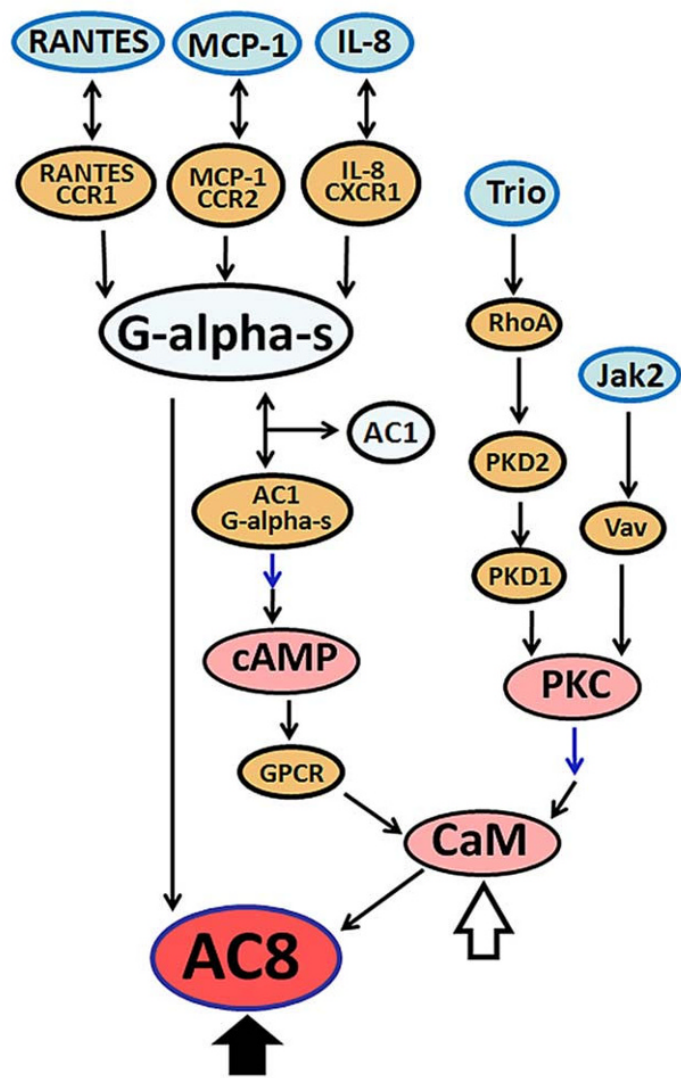

Figure 4

Bioinformatics analysis of candidate molecular signaling networks of genes differentially expressed in [BF/S+L/Ep]-treated iDCs. The TRANSPATH Professional 7.I database was searched to assess the possible signaling pathways, networks or potential interactions among the responsive genes/target molecules in iDCs treated with [BF/ $\mathrm{S}+\mathrm{L} /$ Ep]. The 20 genes that were up- or down-regulated at least 5-fold over controls were analyzed. Specifically, connections (hits) within 7 genes were employed as the parameter for the current search. Two postulated key molecules/pathways, Adenylate cyclase (AC8) and calmudulin (CaM), responsive to $[\mathrm{BF} / \mathrm{S}+\mathrm{L} / \mathrm{EP}]$ treatment were indicated indicated by thick and thin arrows, respectively.

have been recently recognized as a promising cell system for ex vivo/in vitro tissue culture manipulations for potential clinical application as tumor vaccines for cancer therapy [23].

Initially, we used the expression of a highly specific cellsurface and DC maturation maker, CD83, as a key indicator for assessing possible immune modulatory effects of Echinacea extracts on human DCs. The butanol fraction $[\mathrm{BF} / \mathrm{S}+\mathrm{L} / \mathrm{Ep}]$ significantly stimulated but the ethylacetate (EA) fraction greatly inhibited CD83 expression in iDCs, which suggests a possible immune modulatory effect of $[\mathrm{BF} / \mathrm{S}+\mathrm{L} / \mathrm{Ep}]$ on the maturation of iDCs and that different sub-fractions of the phytocompound mixtures/herbal extracts could confer different or even opposite biological activities. These findings thus strongly suggest the urgent need for a clear, specific and stringent definition(s) of the extraction, fractionation and plant-tissue usage of the medicinal herb preparations and the derived phytocompounds for both laboratory experimental studies and commercial applications. The lack of such definition and information has already raised public concern.

Since our results on CD83 protein expression suggested that the $[\mathrm{BF} / \mathrm{S}+\mathrm{L} / \mathrm{Ep}]$ may stimulate the maturation of iDCs, we subjected this butanol fraction to HPLC analysis to characterize the major components and some possible active compounds. We identified seven specific phytocompounds, namely hypoxanthine, caffeic acid, chlorogenic acid, cichoric acid, rutin, quercetin 3-O-rhamnosyl$(1 \rightarrow 6)$-galactoside, and kaempferol 3-O-rhamnosyl$(1 \rightarrow 6)$-galactoside from the $[\mathrm{BF} / \mathrm{S}+\mathrm{L} / \mathrm{Ep}]$ fraction. The content of two major compounds cichoric acid (4) and rutin (7) were quantified, and this data could be used as chemical fingerprints and index compounds for future study and standardization of the bioactive [BF/S+L/Ep] fraction of E. purpurea. Potential future application of the $[\mathrm{BF} / \mathrm{S}+\mathrm{L} / \mathrm{Ep}]$ fraction for use as remedy, nutraceutical or food supplement would have to wait until future studies are carried out with the considerations of appropriate dosage, bio-activity and defined immuno-modulatory functions to be assayed under in vivo conditions.

Use of the Affymetrix microarray analysis revealed approximately $10 \%$ of the whole human genome effectively expressed in DCs (data not shown). A total of 400 genes ( $\approx 18 \%$ of the expressed genes) were differentially or specifically regulated during the differentiation or maturation of iDCs. The top 20 genes with significantly up regulated expression ( $>3$-fold change) at $4 \mathrm{~h}$ post-treatment with $[\mathrm{BF} / \mathrm{S}+\mathrm{L} / \mathrm{Ep}]$ include some important earlyresponsive chemokine genes such as CCL2, CCL5 and IL8 , previously reported to play important roles in inflammatory responses [38]. Although treatment with cichoric acid did not affect CD83 expression, as was observed for $[\mathrm{BF} / \mathrm{S}+\mathrm{L} / \mathrm{Ep}]$, it nonetheless up-regulated a similar subset of early response genes. Additional analysis of genes with overlapping expression on treatment with both $[\mathrm{BF} / \mathrm{S}+\mathrm{L} /$ Ep] and cichoric acid revealed that some of the interferoninducible proteins, including IFI44, IFI78 (Table 3), IFIT1 and the interferon alpha-inducible protein (Table 1B), were all down-regulated at $24 \mathrm{~h}$ post-treatment. Thus, several key chemokine genes are likely involved in the early response to treatment with specific Echinacea phytocompounds, and another set of interferon-inducible genes belong to the group of late-responsive genes. We also per- 
Table 4: Up- or down-regulation of proteins in human iDCs in response to treatment with [BF/S+L/Ep] or cichoric acid

\begin{tabular}{|c|c|c|c|c|c|}
\hline \multirow[t]{3}{*}{ Protein Name } & \multicolumn{4}{|c|}{$\begin{array}{c}\text { Protein Expression Ratio: Phytocompound Treated/Control } \\
\text { (in 0.1\% DMSO, Untreated) }\end{array}$} & \multirow[t]{3}{*}{$\begin{array}{l}\text { Accession Number } \\
\text { (SwissProt Data Base) }\end{array}$} \\
\hline & \multicolumn{2}{|c|}{$[B F / S+L / E p](75 \mathrm{ug} / \mathrm{ml})$} & \multicolumn{2}{|c|}{ Cichoric Acid (50 ug/ml) } & \\
\hline & $12 \mathrm{~h}$ & $24 \mathrm{~h}$ & $12 \mathrm{~h}$ & $24 \mathrm{~h}$ & \\
\hline \multicolumn{6}{|l|}{ Up-regulation in protein expression } \\
\hline Gelsolin & 1.12 & 1.1 & 2.37 & 5.09 & $\underline{\mathrm{P} 06396}$ \\
\hline Macrophage capping protein & 1.39 & 1.13 & 1.31 & 1.34 & $\overline{\mathrm{P} 40121}$ \\
\hline Actin-related protein 3 & 0.97 & 1.04 & 1 & 1.23 & $\overline{P 61158}$ \\
\hline Coronin-IC & 2.55 & 0.71 & 1.74 & 1.1 & Q9ULV4 \\
\hline Beta adducing & 1.1 & 1.49 & 1.34 & 1.69 & P35612 \\
\hline Rho GDP-dissociation inhibitor I & 0.94 & 1.16 & 0.83 & 1.49 & $\overline{\mathrm{P} 52565}$ \\
\hline Rab GDP dissociation inhibitor beta & 0.9 & 1.37 & 0.88 & 1.46 & $\overline{\mathrm{P} 50395}$ \\
\hline T-complex protein I, epsilon subunit & 1.29 & 1.03 & 1.17 & 1.44 & $\overline{\mathrm{P} 48643}$ \\
\hline Serum albumin [Precursor] & 1.24 & 1.1 & 1.23 & 0.87 & $\underline{\mathrm{P} 02768}$ \\
\hline Vimentin & 2.44 & 0.77 & 1.1 & 0.7 & $\underline{\mathrm{P} 08670}$ \\
\hline Protein disulfide-isomerase A3 [Precursor] & 1.09 & 1.21 & 0.93 & 1.03 & $\underline{\mathrm{P} 30101}$ \\
\hline Carbonic anhydrase II & 1.76 & 1.16 & 1.32 & 1.01 & $\overline{\mathrm{P} 00918}$ \\
\hline Catalase & 1.14 & 1.21 & 1.28 & 1 & $\underline{\mathrm{P} 04040}$ \\
\hline Superoxide dismutase [Mn], mitochondrial & 1.72 & 1.23 & 1.09 & 0.84 & $\overline{\mathrm{P} 04179}$ \\
\hline Peroxiredoxin 6 & 1 & 1.13 & 1.1 & 1.31 & $\overline{\mathrm{P} 30041}$ \\
\hline Biliverdin reductase A [Precursor] & 1.21 & 1.05 & 1.32 & 1.27 & $\overline{\mathrm{P} 53004}$ \\
\hline Poly(rC)-binding protein I & 0.87 & $\mathrm{I}$ & 0.79 & 1.31 & $\underline{Q} 15365$ \\
\hline WD-repeat protein I & 1.54 & 1.17 & 1.74 & 1.47 & $\underline{075083}$ \\
\hline TFIIH basal transcription factor complex helicase subunit & 0.88 & 1.06 & 0.86 & 1.36 & $\underline{\mathrm{P} 18074}$ \\
\hline Chloride intracellular channel protein I & 0.98 & 1.04 & 0.94 & 1.32 & $\overline{000299}$ \\
\hline Potassium voltage-gated channel subfamily $\mathrm{H}$ member 5 & 0.89 & 1.07 & 1.14 & 1.68 & $\overline{\mathrm{O} 8 \mathrm{NCM} 2}$ \\
\hline \multicolumn{6}{|l|}{ Down-regulation in protein expression } \\
\hline Cofilin, non-muscle isoform & 0.75 & 0.84 & 0.09 & 0.42 & $\underline{\mathrm{P} 23528}$ \\
\hline F-actin capping protein beta subunit & 0.99 & 1.09 & 0.87 & 1.23 & P47756 \\
\hline Actin-related protein $2 / 3$ complex subunit 2 & 0.83 & 0.53 & 0.94 & 0.58 & $\overline{015144}$ \\
\hline Profilin-I & 0.84 & 0.76 & 0.6 & 0.51 & $\mathrm{P} 07737$ \\
\hline Lamin $A / C$ & 0.81 & 0.69 & 0.45 & 0.76 & $\overline{\mathrm{P} 02545}$ \\
\hline Phosphoglycerate mutase I & 1.3 & 0.83 & 0.89 & 1.76 & $\underline{P 18669}$ \\
\hline Superoxide dismutase [Cu-Zn] & 0.84 & 0.99 & 0.78 & 1.48 & $\overline{\mathrm{P} 00441}$ \\
\hline Dihydrolipoyl dehydrogenase, mitochondrial [Precursor] & 0.97 & 0.61 & 1.12 & 0.82 & $\overline{\text { P09622 }}$ \\
\hline Galactose mutarotase & 1.08 & 1.05 & 1.32 & 1.46 & $\overline{096 C 23}$ \\
\hline $\begin{array}{l}\text { Delta3, 5-delta2, 4-dienoyl-CoA isomerase, mitochondrial } \\
\text { [Precursor] }\end{array}$ & 1.24 & 0.84 & 1.23 & 0.22 & Q13011 \\
\hline Dihydropyrimidinase related protein-2 & 0.96 & 1.22 & 0.77 & 1.74 & 이 6555 \\
\hline $26 \mathrm{~S}$ proteasome non-ATPase regulatory subunit 13 & 0.94 & 1.32 & 0.95 & 1.42 & Q9UNM6 \\
\hline $60 \mathrm{~S}$ acidic ribosomal protein $\mathrm{PO}$ & 1.07 & 1.02 & 0.7 & 1.13 & P05388 \\
\hline Heterogeneous nuclear ribonucleoprotein $\mathrm{H}$ & 1 & 0.7 & 0.74 & 0.52 & $\overline{\mathrm{P} 31943}$ \\
\hline
\end{tabular}




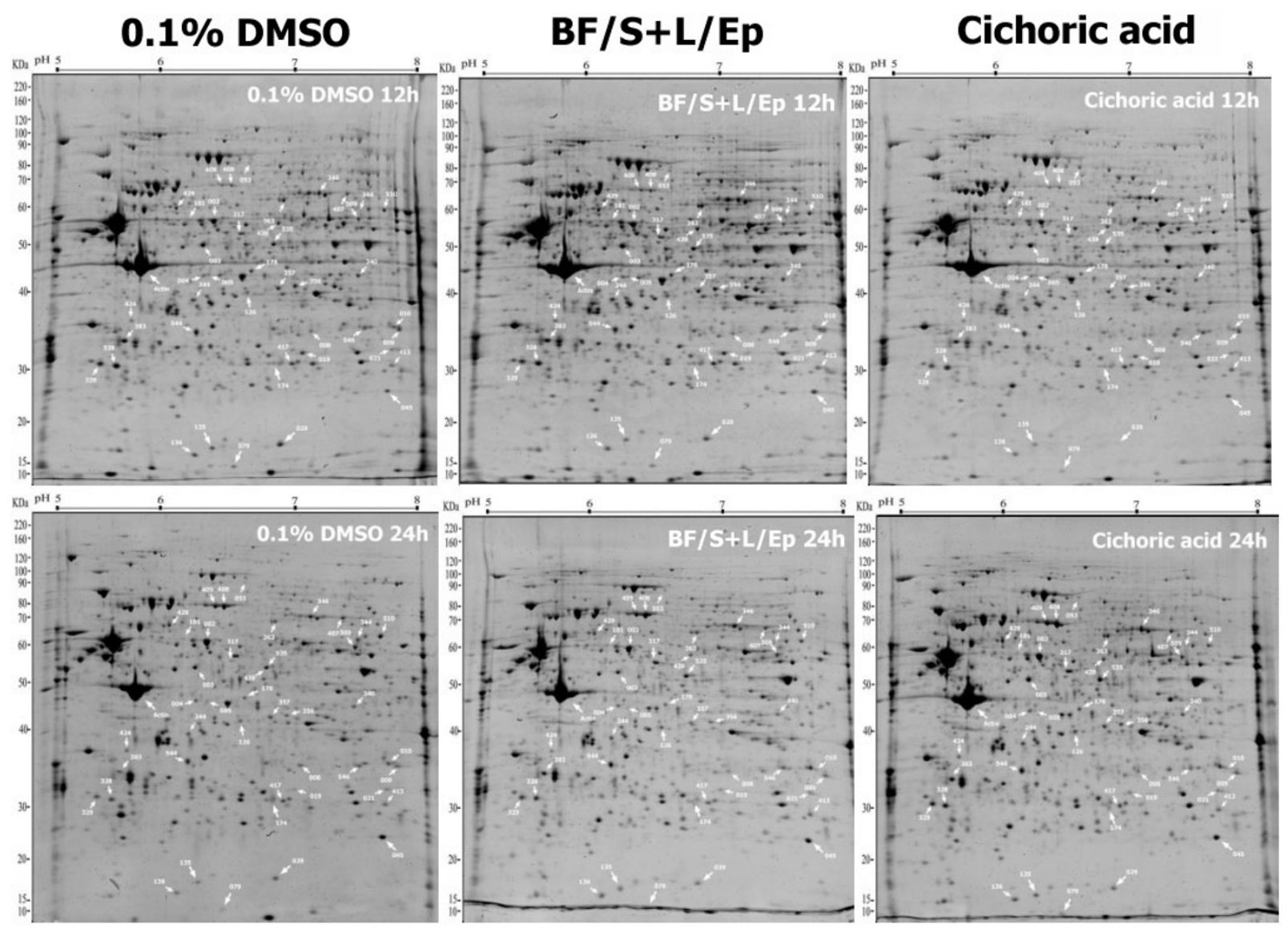

\section{Figure 5}

Differential expression pattern of proteins in iDCs treated with [BF/S+L/Ep] and derived phytocompounds. Human iDCs in culture were treated with $0.1 \%$ DMSO (vehicle control), [BF/S+L/Ep] (75 $\mu \mathrm{g} / \mathrm{ml})$ and cichoric acid (50 $\mu \mathrm{g} / \mathrm{ml})$ for 12 or 24 h. Aliquots of equal amounts of solubilized total proteins from various test cell samples were analyzed by 2-D gel electrophoresis and MALDI-TOF-MS. Approximately I,300 protein spots were detected in iDCs. Seventy gels were used for the present study, and highly similar results were obtained from three independent experiments, unless indicated otherwise.

formed gene-clustering analysis to classify the gene expression patterns in human iDCs. A total of 382 genes were grouped into six clustering sets on the basis of their expression in response to $[\mathrm{BF} / \mathrm{S}+\mathrm{L} / \mathrm{Ep}]$ (Figure 3). In contrast, cichoric acid and vehicle treatment produced no clustering differences, which suggests the lack of a multidomain or substantial effect of cichoric acid on most expressed genes in iDCs.

We have identified a hypothetical signaling network involving $[\mathrm{BF} / \mathrm{S}+\mathrm{L} / \mathrm{Ep}]$-induced early response genes such as CCL2 (MCP-1), IL-8, CCL5, JAK2 and TRIO (Figure 4). This signaling network revealed possible activation of CAMP and PKC pathways leading to the regulation of AC8 through a $\mathrm{Ca}^{2+}$ receptor, calmodulin. Previous studies have demonstrated that activation of cAMP induces DC maturation and migration [39]. PKC plays an important role in DC differentiation and antigen presenting function [40]. In addition, $\mathrm{Ca}^{2+}$ dependent pathways have been shown to regulate DC maturation and migration [41]. Our results on increased expression of CD83 maturation marker coupled with candidate signal transduction pathways strongly suggest that $[\mathrm{BF} / \mathrm{S}+\mathrm{L} / \mathrm{Ep}]$ may enhance the iDC maturation and function, which warrants further systematic investigation.

2-D gel electrophoresis revealed 100 of the 1,300 detectable protein spots $(\approx 7.7 \%)$ affected in iDCs after 12 - or 24 $\mathrm{h}$ treatment with $[\mathrm{BF} / \mathrm{S}+\mathrm{L} / \mathrm{Ep}]$. We suggest that this $7.7 \%$ change in iDC protein levels may reflect a marked change in protein expression, since the other cell types we have studied in parallel (e.g., primary T-cells) showed only a $3 \%$ to $5 \%$ change (data not shown). We observed significant up-regulation of antioxidant defense enzymes such 


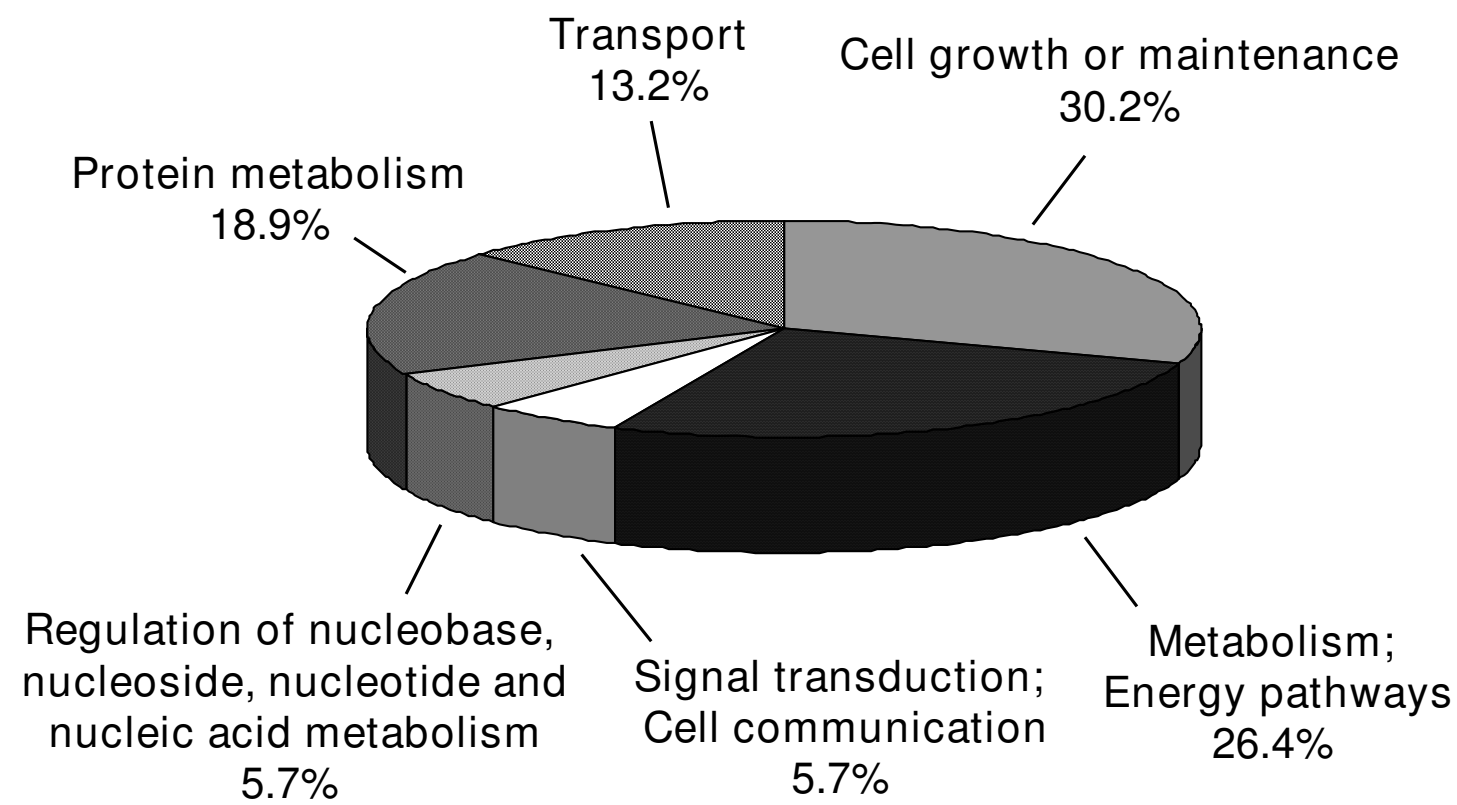

Figure 6

Grouping of the identified human iDC proteins expressed in response to treatment with [BF/S+L/Ep], according to their known cellular or biochemical functions. Assignment of biochemical functions of each protein involved with the use of information from the Swiss-Prot database at the ExPASY Molecular Biology Server http://www.expasy.org.

as Mn-SOD, catalase and peroxiredoxin 6 in iDCs in response to $[\mathrm{BF} / \mathrm{S}+\mathrm{L} / \mathrm{Ep}]$ and cichoric acid. Endogenous antioxidants have been reported to play key role in dendritic cell survival, and ability to induce $\mathrm{T}$ cell activation and regulate the polarity of immune responses [42,43]. Several cytoskeletal and actin-binding proteins (Table 4) were significantly up-regulated in $[\mathrm{BF} / \mathrm{S}+\mathrm{L} / \mathrm{Ep}]$ or cichoric acid treated iDCs. In DC, the changes in actin cytoskeleton components are essential for the formation of its characteristic dendrites and veils, as well as an immunological synapse necessary for antigen presentation [44]. In addition, actin cytoskeleton rearrangement is important for the motility and migration of cells and may influence the migration of DC to lymph nodes during their maturation [45]. Results from 2-D gel electrophoresis (Figures 7A and $8 \mathrm{~A}$ ) and Western blot analyses (Figures 7B and 8B) confirmed in general the trend of changes in differential expression of Mn-SOD and cofilin. We therefore hypothesize that a specific group of phytocompounds in Echinacea may turn on the antioxidant defense system and regulate the rearrangement of cytoskeleton, which in turn may contribute to the positive enhancement of the immunemodulatory activities of DCs.
The present study has identified a pool of known or unknown genes associated with the differential expression of a spectrum of cytokines and chemokines and other immune cell activities in response to treatment with Echinacea compounds in DCs (Tables 1 to 4, and Figure 3). In addition, changes in level of molecules related to cell adhesion, immune-response and antigen presentation were observed in this human DC model, providing candidate target genes/proteins for future cross-talk studies of the biology of human DCs. These differentially expressed genes and proposed candidate signaling pathways/networks obtained via bioinformatics approaches have provided us with useful potential clues and molecular targets for future studies of molecular mechanisms underlying specific immune modulatory effect(s) of important medicinal herb Echinacea purpurea and derived phytocompounds in iDCs.

\section{Conclusion}

Since dendritic cells are well characterized and recognized as potent antigen presenting cells and have been shown to play critical roles in both innate and adaptive immunities, we have employed human DCs for functional genomics studies to evaluate possible immuno-modulatory effects 

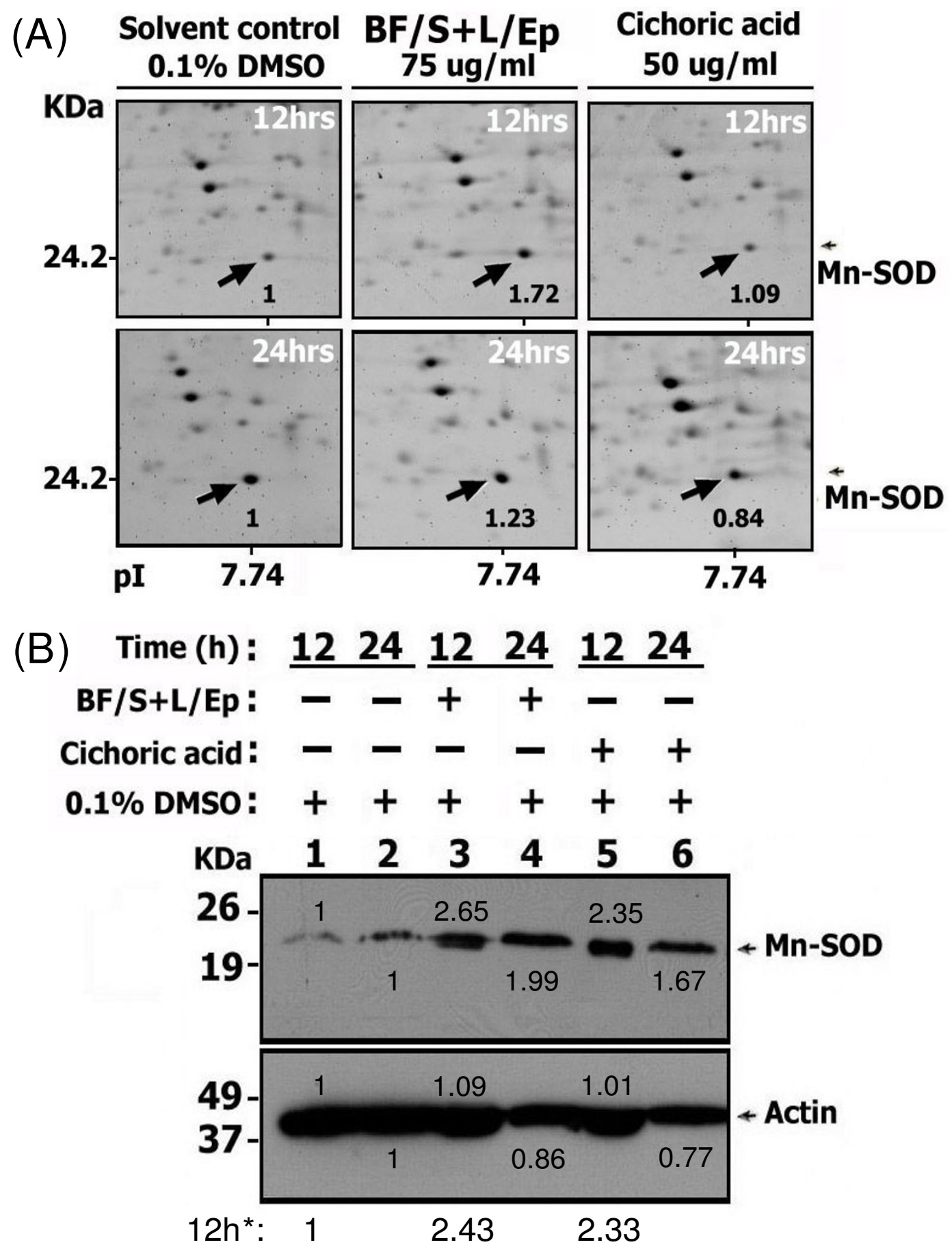

Figure 7

Confirmation of the 2-D gel proteomic results on up-regulation of Mn-SOD protein expression with Western blot analysis. (A) Differential expression of Mn-SOD protein in iDCs treated with $[\mathrm{BF} / \mathrm{S}+\mathrm{L} / \mathrm{Ep}](75 \mu \mathrm{g} / \mathrm{ml})$, cichoric acid $(50$ $\mu \mathrm{g} / \mathrm{ml}$ ) or vehicle control, at both 12 and $24 \mathrm{~h}$ post-treatment, as revealed by 2-D gel electrophoresis, SYPRO Ruby dye staining, and quantification by PDQuest analysis. The arrows indicate the Mn-SOD protein spots detected in different treatments. The expression ratio compared to control gel is shown in black. (B) Western blot analysis of expression of Mn-SOD and actin in human iDCs treated with phytocompounds. Total cellular proteins were extracted and separated by 10\% SDS-PAGE, and Western blot analysis performed with anti-Mn-SOD or anti-actin antibodies. Actin was used as a sample-loading control. Similar results were obtained from three independent experiments. 
(A)

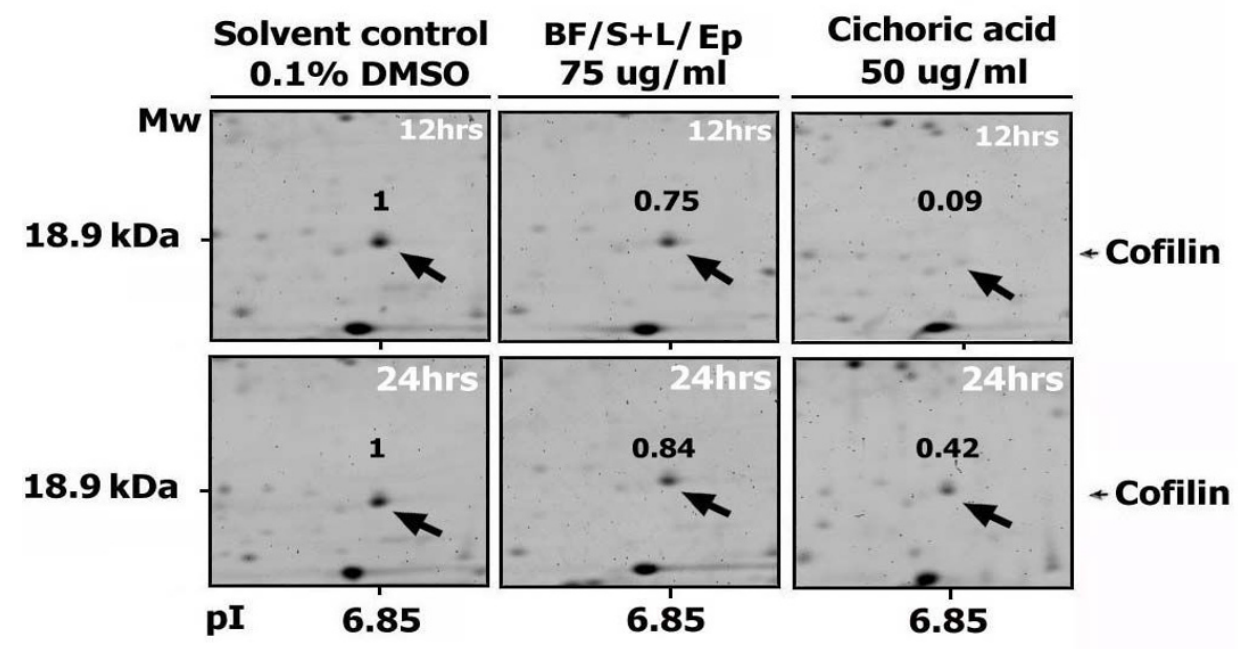

(B) iDC treated for 12 hours
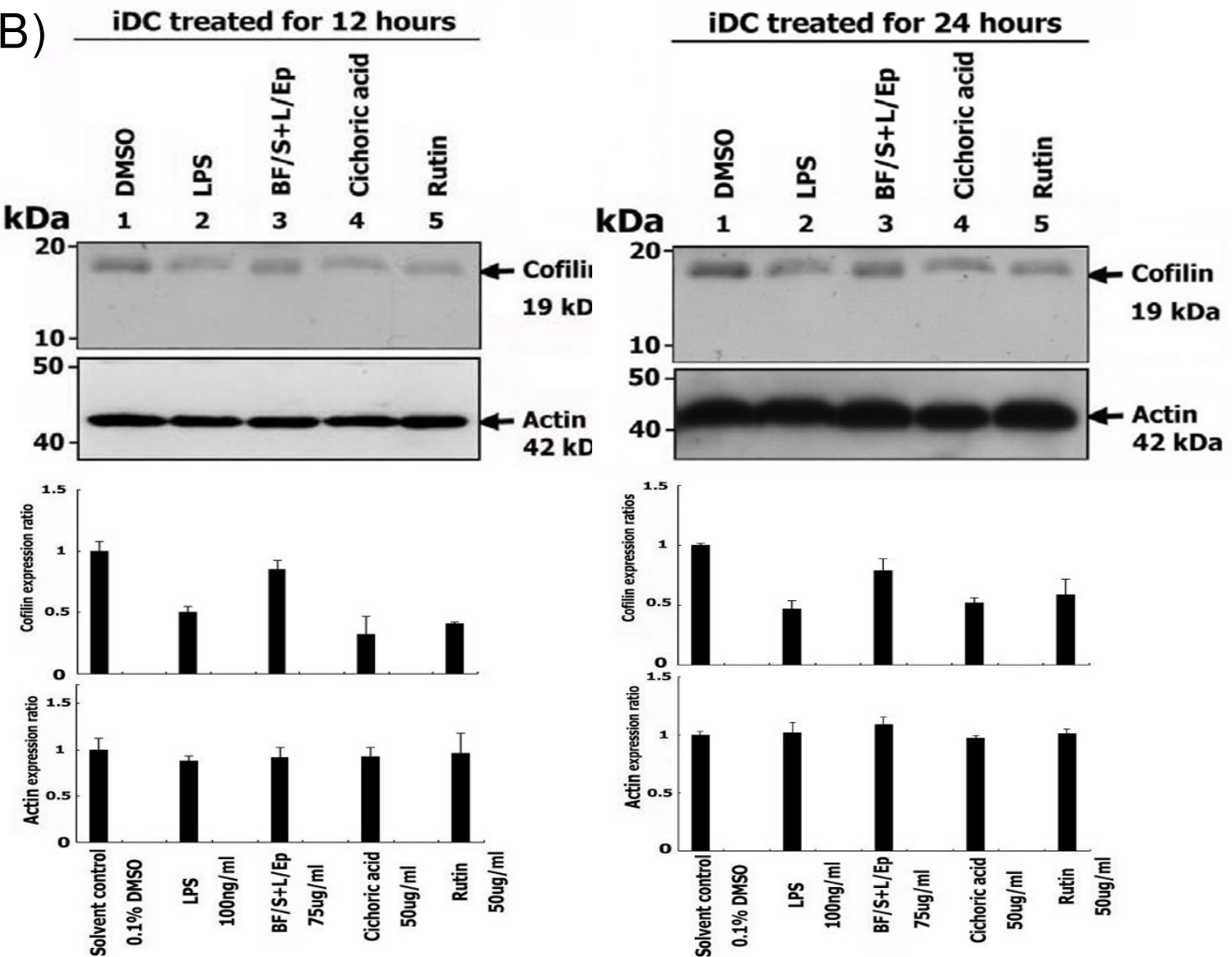

Figure 8

Confirmation of the 2-D gel proteomic results on down-regulation of cofilin protein expression with Western blot analysis. (A) Differential expression of cofilin in human iDCs treated with $[\mathrm{BF} / \mathrm{S}+\mathrm{L} / \mathrm{Ep}](75 \mu \mathrm{g} / \mathrm{ml})$, cichoric acid $(50 \mu \mathrm{g} /$ $\mathrm{ml}$ ) or vehicle control, at 12 and $24 \mathrm{~h}$ treatment, as revealed by 2-D gel electrophoresis. (B) Western blot analysis of expression of cofilin in human iDCs. Other experimental details are the same as described in Figure 7. Similar trends were observed in three independent experiments. 
of specific phytocompound mixtures from a popular medicinal herb extract, Echinacea purpurea. Specific and differential gene expression patterns were detected in time-course experiments of iDCs treated with the bioactive phytocompound fraction ([BF/S+L/Ep]) and its major index compound (cichoric acid). Transcritome analyses showed significant up regulation of specific chemokine and cytokine genes, including CXCL2, CCL5, CCL2, IL-8, IL-1 $\beta$ and IL-18, within $4 \mathrm{~h}$ after [BF/S+L/Ep] treatment of iDCs. Bioinformatics studies suggested that a key molecular signaling network involving a number of the detected immune-modifier genes may lead to the activation of a downstream adenylate cyclase 8 activities, contributing to the observed cellular and molecular activities in test cells. Subsequent proteomic studies further showed that expression of specific antioxidation and cytoskeletal proteins, known to play important cellular physiological roles in DCs, are increased in cichoric acid or [BF/S+L/Ep]-treated cells. Based on these results, we conclude from this study that specific phytocompound mixtures present as major or active components in the test traditional herb may confer defined and significant immuno-modulatory effects on specific immune cell types. The candidate target molecules and molecular signaling mechanisms identified from this and previous study [25] provide us with useful information and hypothesis for future studies on characterization of human DCs in response to treatment with medicinal phytocompounds at the transcriptome and proteome levels.

\section{Methods}

\section{Plant materials and crude extract preparations}

E. purpurea plants at flowering stage were harvested from a reputable organic farm in Puli, Nantou County, Taiwan. Stem and leaf $(\mathrm{S}+\mathrm{L})$ tissues of fresh plants were extracted at room temperature by imbibition with $70 \%$ aqueous ethanol as previously reported [25]. The total $70 \%$ ethanolic extracts were concentrated $(1 \mathrm{~L})$ and successively partitioned with ethyl acetate $(1 \mathrm{~L} \times 3$ times $)$ and $n$-butanol ( $1 \mathrm{~L} \times 3$ times) to yield three sub-fractions, designated as the $\mathrm{EA}, \mathrm{BuOH}$ and Water fractions. The percentage of yield for the three fractions was calculated as $10.3 \%$, $7.23 \%$, and $77.2 \%$, respectively, of the $70 \%$ ethanolic extracts in dry weight.

\section{Generation of human dendritic cells}

Monocyte-derived dendritic cells were generated from peripheral blood mononuclear cells (PBMCs) isolated from healthy volunteers blood samples as described previously [25]. Briefly, CD14+ monocytes were isolated by passing the PBMCs through a magnetic cell separation system (Miltenyi Biotec, Germany). CD14+ cells at 95\% purity were cultured for 7 days in AIM-V medium in the presence of GM-CSF $(1000 \mathrm{U} / \mathrm{ml})$ and IL-4 $(500 \mathrm{U} / \mathrm{ml})$ to obtain immature dendritic cells (iDCs).

\section{Flow cytometry}

At $24 \mathrm{~h}$ after treatment with E. purpurea crude extract, the $\mathrm{S}+\mathrm{L}$ extract, or the three subfractions, iDCs were harvested and analyzed by immunofluorescence staining. Monoclonal antibodies labeled with fluorescent dyes i.e., HLADR-FITC, CD14-PE, CD32-PE, and CD83-FITC from Immunotech (Fullerton, CA) and CD86-FITC from Pharmingen (Fullerton, CA) were used. After incubation with specific antibodies at $4{ }^{\circ} \mathrm{C}$ for $30 \mathrm{~min}$, cells were washed twice with PBS and fixed with $1 \%$ paraformaldehyde, and subjected to analysis using a Coulter EPICS XL flow cytometer (Beckman/Coulter, Durham, NC).

\section{Cell viability assay}

Human iDCs $\left(4 \times 10^{5}\right.$ cells $\left./ \mathrm{ml}\right)$ were incubated with $0.1 \%$ DMSO (vehicle control), test plant extract or derived phytochemicals in basal medium in 96-well plates for $24 \mathrm{~h}$ in a $5 \% \mathrm{CO}_{2}$ incubator. All treatments were performed in triplicate. Viability of iDCs was determined by MTT assay, and percentage cell viability was calculated as previously described [25]. The derived plant extracts from E. purpurea were examined by a Limulus Amebocyte Lysate (LAL) test (E-TOXATEâ Kits, Sigma, MO, USA) for detection of possible endotoxin (LPS) contamination before bioactivity assays.

\section{Phytocompound isolation}

The BuOH fraction of the $\mathrm{S}+\mathrm{L}$ tissues of $E$. purpurea, designated as $[\mathrm{BF} / \mathrm{S}+\mathrm{L} / \mathrm{Ep}]$ hereafter, was subjected to chomatography on RP-18 silica gel with the $\mathrm{H}_{2} \mathrm{O} / \mathrm{MeOH}$ solvent system to yield four fractions. Fraction 1 was further purified by filtration though a Sephadex LH-20 (Amersham Pharmacia Biotech) column with a $\mathrm{H}_{2} \mathrm{O} / \mathrm{MeOH}$ gradient solvent system to yield three sub-fractions. RP-18 highperformance liquid chromatography (HPLC) column (Phenomenex Luna, $5 \mu \mathrm{m} \mathrm{C18}, 250 \times 10 \mathrm{~mm}$ ) with a solvent system, $0.05 \%$ TFA $/ \mathrm{H}_{2} \mathrm{O}$ (solvent $\mathrm{A}$ ) and $0.05 \%$ TFA/ $\mathrm{MeOH}$ (solvent $\mathrm{B}$ ) and gradient profile (5-5\% for 0 to 5 $\min , 5-20 \%$ for $5-30 \mathrm{~min}$, and $20-50 \%$ for $30-60 \mathrm{~min}$ ) was used for isolation of single compounds. Quantification of the index compounds in the active $[\mathrm{BF} / \mathrm{S}+\mathrm{L} / \mathrm{Ep}]$ fraction involved HPLC. The peak areas corresponding to the content of candidate compounds of a known concentration of the active fraction were calculated on the basis of a standard calibration curve of the individual index compounds. The HPLC profile and the relative content of the index compounds were routinely used for quality control.

\section{Chemical fingerprinting of the active [BF/S+L/Ep] fraction using LCIMS}

LC/MS was employed to analyze the chemical fingerprint of the $[\mathrm{BF} / \mathrm{S}+\mathrm{L} / \mathrm{Ep}]$ fraction. LC/MS was carried out using a ThermoFinnigan LCQ Advantage ion trap mass spectrometer equipped with an Agilent 1100 series liquid 
chromatographer, at the Metabolomics Core Facility of the Agricultural Biotechnology Research Center, Academia Sinica, Taiwan. Aliquot of a $5 \mu \mathrm{l}$ sample of [BF/ $\mathrm{S}+\mathrm{L} / \mathrm{Ep}](10 \mathrm{mg} / \mathrm{ml})$ was injected and analyzed at a flow rate of $0.2 \mathrm{ml} / \mathrm{min}$. HPLC profiling involved an RP-18 col-

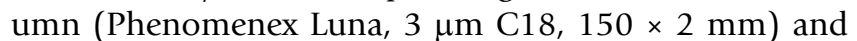
eluted compounds detected by UV absorbance at 254 and $330 \mathrm{~nm}$ before MS analysis. The solvent gradient for HPLC was $0.05 \%$ TFA $/ \mathrm{H}_{2} \mathrm{O}$ (solvent A) and $0.05 \%$ TFA/ $\mathrm{MeOH}$ (solvent B): $5-5 \%$ for 0 to $5 \mathrm{~min}, 5-20 \%$ for $5-30$ $\min , 20-45 \%$ for $30-40 \mathrm{~min}$, and $45-50 \%$ for $40-50$ min). Ionization involved the positive ion mode for all analyses.

\section{DNA microarray analysis of differential gene expression patterns}

Total RNA was isolated by use of TRIzol ${ }^{\circledR}$ Reagent (Invitrogen) according to the manufacturer's instructions to generate cRNA targets. A total of $7 \mu \mathrm{g}$ of RNA from each sample was used to synthesize the first-strand CDNA with $\mathrm{T}_{7}$-Oligo (dT) primer and $\mathrm{T} 7 \mathrm{RNA}$ polymerase by in vitro transcription reaction. The biotinylated cRNA products were then cleaned according to the Affymetrix protocol. Aliquots of $15 \mu \mathrm{g}$ of total cRNA per sample were then hybridized to the Affymetrix gene chip HG-U133A containing approximately 22,283 probe sets following the manufacturer's instructions. Images were obtained by use of standard Affymetrix scanners. The cell intensities and detection from the nine hybridized oligonucleotide microarrays were derived by use of the Affymetrix Microarray Suite 5 (MAS 5.0) with default settings. Normalization was by dChip with the PM-MM model-based approach to obtain the expression indices for each probe set [46]. The pool of the replicate arrays, CM-00h-1 and CM-00h-2, was used as a baseline for normalization and was applied to the calculation of $\log 2$ ratios, $M$, for the test arrays. Comparative expression analysis of the two arrays by the MAS 5.0 system reported a level of "no change in gene expression pattern" of $98.0 \%$ (with a correlation of 0.9916 ). This high reproducibility of results indicates very high reliability and very low variation of our experimental data obtained from the in-house Affymetrix system. The gap statistic and K means analysis were used to distinguish gene clusters as described previously $[47,48]$. The putative signal transduction pathways were analyzed using TRANSPATH Professional 7.1 (BIOBASE Biological Databases, Germany). The microarray data obtained from this study have been deposited to the Gene Expression Omnibus database at NCBI (GEO; http://www.ncbi.nlm.nih.gov/projects/geo/) under the accession number GSE12259.

\section{2-D gel electrophoresis and image analysis}

Total cellular proteins of iDCs were extracted and prepared in $0.3 \mathrm{ml}$ of lysis buffer [7 M urea, $2 \mathrm{M}$ thiourea, 4\% 3,3-cholamidopropyl-dimethylammonio-1-propanesulfonate (CHAPS), 10\% 1,4-dithiothreitol (DTT), 2\% Pharmalyte pH3-10] by vortexing for $1 \mathrm{~h}$, and protein supernatants were collected after ultracentrifugation at $55,000 \mathrm{rpm}$ for $1 \mathrm{~h}$. Protein concentrations were determined using Bio-Rad BCA protein assay kit (Bio-Rad, Hercules, CA). 2-D gel electrophoresis involved the PROTEAN isoelectric focusing and electrophoresis system (Bio-Rad, Hercules, CA) with modification [49]. Briefly, $550 \mu \mathrm{g}$ of protein was diluted in $300 \mu \mathrm{l}$ of rehydration buffer containing $7 \mathrm{M}$ urea, $2 \mathrm{M}$ thiourea, 4\% CHAPS, 2\% 1,4-dithioerythitol, $0.13 \%$ Biolyte 5-8 (Bio-Rad) and $0.07 \%$ Biolyte 8-10 (Bio-Rad). Protein samples were loaded onto IPG strips (Bio-Rad; $17 \mathrm{~cm}, \mathrm{pH}$ 5-8) through passive rehydration overnight. Proteins underwent electro focusing analysis in slow-ramping mode with a final voltage of $8,000 \mathrm{~V}$ for a total of 25,000 Vh. Following a twostep equilibration, IPG strips were processed by $10-16 \%$ gradient SDS-PAGE and electrophoretic separation at 200 V. Gels were then fixed and stained with SYPRO-Ruby fluorescent stain (Molecular Probes; Eugene, OR) according to the manufacturer's instructions. Stained gels were visualized by a Typhoon scanner system (Amersham). Digitalized gel images were analyzed by 2-D PDQuest, V.T.O. (Bio-Rad). Protein spots on gels were automatically detected with use of the PDQuest system. The 2-D gel images of iDCs proteins obtained with IPG strips ( $\mathrm{pH} 5-$ 8 ) were matched separately, with each match set containing 9 images, with 3 images for control replicates. The image with the highest number of spots was selected as the master gel. Automatically detected images of protein spots in test gels were then manually edited to include the low intensity spots and corrected for spot artifacts. For the match set containing images from pI 5-8, the spot volume (intensity integrated over the spot area) was normalized to the total volume of spots in the gel. Data were then exported to Microsoft Excel.

\section{Protein identification by MALDI-TOF-MS}

Protein extraction was performed as previously described [50]. Briefly, each gel spot was cut into small pieces with a scalpel, washed with $700 \mu$ of double distilled $\mathrm{H}_{2} \mathrm{O}$, and subjected to reduction reaction by DTT. Alkylation reaction then carried out by adding $55 \mathrm{mM}$ iodoacetamide for $1 \mathrm{~h}$ at room temperature in the dark. Gel spots were washed with ammonium carbonate then acetonitrile. Gel pieces were dried and then immersed in trypsin solution. The in-gel digestion was performed at $37^{\circ} \mathrm{C}$ overnight. Resulting tryptic peptides were extracted twice from the test gel into $70 \%$ acetonitrile/5\% $\mathrm{HCOOH}$ by sonication then centrifugation. The combined supernatant was dried under a Savant Speed Vac, and $6 \mu$ l of $1 \% \mathrm{HCOOH}$ was added to each test sample. Protein identification by MALDI-Q-TOF-MS [51] was performed at the Proteomics Core Facility of the Institute of Biological Chemistry, 
Academia Sinica. The MS data with monoisotopic peptide masses were searched against the NCBI protein database with use of the MASCOT search engine (Matrix Science; London, UK). Variable modifications, methionine oxidation and cysteine carbamidomethylation were taken into account in our data analyses.

\section{Western blot analysis}

Total protein was isolated from test iDCs with ice-cold lysis buffer $(150 \mathrm{mM} \mathrm{NaCl}, 0.5 \%$ Triton X-100, $50 \mathrm{mM}$ Tris-HCl (pH 7.4), 20 mM EGTA, 1 mM dithiothreitol (DTT), and protease inhibitor cocktail tablets) for 10 min and centrifuged at $12,000 \times g$ for $20 \mathrm{~min}$. Protein samples were subjected to western blotting as described previously [52]. Briefly, the proteins were detected after overnight incubation at $4{ }^{\circ} \mathrm{C}$ with $1: 1000$ dilution of Mn-SOD or cofilin polyclonal antibodies (Millipore, MA, USA). Equal protein loading was assessed using mouse $\beta$-actin (Sigma Chemical Co., St. Louis, U.S.A). The proteins were visualized with an enhanced chemiluminescence (ECL) detection kit (Amersham Pharmacia Biotech, Buckinghamshire, UK).

\section{Authors' contributions}

CYW served as key experimenter and author of the draft manuscript. VS improved the clarity by critical revision and reorganization of the manuscript, and incorporated some parts of the discussion section. MTC designed, optimized and completed the $2 \mathrm{D}$ gel/proteome experiments. $\mathrm{CCH}$ performed metabolite profiling and compound identification. HMW, KCY, CHC \& PIH performed bioinformatics analyses on DNA microarray data as a team. TNW introduced and built the proteome study system of the lab. LFS is Co-PI and Co-correspondent author of this project/manuscript. NSY is PI and principal author of the manuscript. All authors read and approved the final manuscript.

\section{Acknowledgements}

This work was supported by grants from the Genomics and Proteomics Program, Academia Sinica (No. 94F002), Taiwan. We thank Drs. Harry Wilson and Kenrick Deen and Ms. Miranda Loney for editing the manuscript, Drs. Shao-Chih Chiu and Mr. Yi-An Chen for supporting the bioinformatics analysis of microarray data and Mr. Da-Yung Chuang for his technical assistance in phytocompound isolation.

\section{References}

I. Canedy D: Real medicine or medicine show? Growth of herbal sales raises issues about value. New York Times 1998, 23: Cl.

2. Ernst $E$ : The risk-benefit profile of commonly used herbal therapies: Ginkgo, St. John's Wort, Ginseng, Echinacea, Saw Palmetto, and Kava. Ann Intern Med 2002, I36:42-53.

3. Barrett $B$, Kiefer D, Rabago D: Assessing the risks and benefits of herbal medicine: an overview of scientific evidence. Altern Ther Health Med 1999, 5:40-49.

4. Zhai Z, Liu Y, Wu L, Senchina DS, Wurtele ES, Murphy PA, Kohut ML, Cunnick JE: Enhancement of innate and adaptive immune functions by multiple Echinacea species. J Med Food 2007, 10:423-434.
5. Matthias A, Banhury L, Stevenson LM, Leach DN, Lehmann RP: Alkylamides from Echinacea modulate induced immune responses in macrophages. Immunol invest 2007, 36: I I7-130.

6. Goel V, Chang C, Slama J, Barton R, Bauer R, Gahler R, Basu T: Echinacea stimulates macrophage function in the lung and spleen of normal rats. I Nutr Biochem 2002, 13:487.

7. McCann DA, Solco A, Liu Y, Macaluso F, Murphy PA, Kohut ML, Senchina DS: Cytokine- and interferon-modulating properties of Echinacea spp. root tinctures stored at $\mathbf{- 2 0}$ degrees $\mathbf{C}$ for 2 years. J Interferon Cytokine Res 2007, 27:425-436.

8. Sharma M, Arnason JT, Burt A, Hudson JB: Echinacea extracts modulate the pattern of chemokine and cytokine secretion in rhinovirus-infected and uninfected epithelical cells. Phytother Res 2006, 20: I47-I52.

9. Hwang SA, Dasgupta A, Actor JK: Cytokine production by nonadherent mouse splenocyte cultures to Echinacea extracts. Clin Chim Acta 2004, 343:161-166.

10. Bodinet C, Lindequist U, Teuscher E, Freudenstein J: Effect of an orally applied herbal immunomodulator on cytokine induction and antibody response in normal and immunosuppressed mice. Phytomedicine 2002, 9:606-6I3.

II. Bauer V, Jurcic K, Puhlmann J, Wagner V: Immunologic in vivo and in vitro examinations of Echinacea extracts. Arzneim Forsch 1998, 38:276-28I.

12. Roesler J, Emmendorffer A, Steinmuller C, Luettig B, Wagner $H$, Lohmann-Matthes ML: Application of purified polysaccharides from cell cultures of the plant Echinacea purpurea to test subjects mediates activation of the phagocyte system. Int J Immunopharmacol |99|, | 3:93|-94|.

13. Luettig B, Steinmuller C, Gifford GE, Wagner H, Lohmann-Matthes ML: Macrophage activation by the polysaccharide arabinogalactan isolated from plant cell cultures of Echinacea purpurea. J Natl Cancer Inst 1989, 81:669-675

14. Sperber SJ, Shah LP, Gilbert RD, Ritchey TW, Monto AS: Echinacea purpurea for prevention of experimental rhinovirus colds. Clin Infect Dis 2004, 38: I367-137I.

15. Taylor JA, Weber W, Standish L, Quinn H, Goesling J, McGann M, Calabrese C: Efficacy and safety of echinacea in treating upper respiratory tract infections in children: a randomized controlled trial. JAMA 2003, 290:2824-2830.

16. Turner RB, Bauer R, Woelkart K, Hulsey TC, Gangemi JD: An evaluation of Echinacea angustifolia in experimental rhinovirus infections. N Engl J Med 2005, 353:34I-348.

17. Linde K, Barrett B, Wölkart K, Bauer R, Melchart D: Echinacea for preventing and treating the common cold. Cochrane Database Syst Rev 2006, 25:CD000530.

18. Barrett BP, Brown RL, Locken K, Maberry R, Bobula JA, D'Alessio D: Treatment of the common cold with unrefined Echinacea . A randomized, double-blind, placebo-controlled trial. Ann Intern Med 2002, 137:939-946.

19. Turner RB, Riker DK, Gangemi JD: Ineffectiveness of Echinacea for prevention of experimental rhinovirus colds. Antimicrob Agents Chemother 2000, 44:1708-1709.

20. Schoop R, Klein P, Suter A, Johnston SL: Echinacea in the prevention of induced rhinovirus colds: a meta-analysis. Clin Ther 2006, 28: 174-183.

21. Shah SA, Sander S, White CM, Rinaldi M, Coleman Cl: Evaluation of Echinacea for the prevention and treatment of the common cold: a meta-analysis. Lancet Infect Dis 2007, 7:473-480.

22. Banchereau J, Briere F, Caux C, Davoust J, Lebecque S, Liu YJ, Pulendran B, Palucka K: Immunobiology of dendritic cells. Annu Rev Immunol 2000, | 8:767-8|I.

23. Gary S: Overcoming Self: A company tries to turn the immune system against cancer. Scientific American 2004, 219:18-19.

24. Reinhard G, Marten A, Kiske SM, Feil F, Bieber T, Schmidt-Wolf IG: Generation of dendritic cell-based vaccines for cancer therapy. Br J Cancer 2002, 86: 1529-1533.

25. Wang CY, Chiao MT, Yen PJ, Huang WC, Hou CC, Chien SC, Yeh KC, Yang WC, Shyur LF, Yang NS: Modulatory effects of Echinacea purpurea extracts on human dendritic cells: a cell- and gene-based study. Genomics 2006, 88:80I-808.

26. Messmer D, Messmer B, Chiorazzi N: The global transcriptional maturation program and stimuli-specific gene expression profiles of human myeloid dendritic cells. Int Immunol 2003, I 5:49|-503. 
27. Brinkeborn RM, Shah DV, Degenring FH: Echinaforce and other Echinacea fresh plant preparations in the treatment of the common cold. A randomized, placebo controlled, doubleblind clinical trial. Phytomedicine 1999, 6: I-6.

28. Benoit RL, Frechette M: Protonation of hypoxanthine, guanine, xanthine, and caffein. Can J Chem 1985, 63:3053-3056.

29. Kinjo JE, Takeshita T, Abe Y, Terada N, Yamashita H: Studies on the constituents of Pueraria lobata . IV. Chemical constituents in the flowers and the leaves. Chem Pharm Bull 1982, 36: I I74-I I79.

30. Cheminat A, Zawatzky R, Becker H, Brouillard R: Caffeoyl conjugates from Echinacea species: structures and biological activity. Phytochemistry 1988, 27:2787-2794.

31. Matsuda H, Morikawa T, Ishiwada T, Managi H, Kagawa M, Higashi Y, Yoshikawa M: Medicinal flowers. VIII. Radical scavenging constituents from the flowers of Prunus mume : structure of prunose III. Chem Pharm Bull (Tokyo) 2003, 5 I:440-443

32. Morishita H, Takai Y, Yamada H, Fukuda F, Sawada M: Caffeoyltryptophan from green robusta coffee beans. Phytochemistry 1987 , 26: I195-1196.

33. Nowak $S$, Wolbis M: Flavonoids from some species of genus. Scopolia Jacq Acta Pol Pharm 2002, 59:275-280.

34. Chiang YM, Chuang DY, Wang SY, Kuo YH, Tsai PW, Shyur LF: Metabolite profiling and chemopreventive bioactivity of plant extracts from Bidens pilosa. J Ethnopharmacol 2004, 95:409-4I9.

35. Raduner S, Majewska A, Chen JZ, Xie XQ, Hamon J, Faller B, Altmann $\mathrm{KH}$, Gertsch J: Alkylamides from Echinacea are a new class of cannabinomimetics. Cannabinoid type 2 receptor-dependent and -independent immunomodulatory effects. J Biol Chem 2006, 28I: | 4 | $92-14206$.

36. Gertsch J, Schoop R, Kuenzle U, Suter A: Echinacea alkylamides modulate TNF-alpha gene expression via cannabinoid receptor CB2 and multiple signal transduction pathways. FEBS Lett 2004, 577:563-569.

37. Le Naour F, Hohenkirk L, Grolleau A, Misek DE, Lescure P, Geiger JD, Hanash S, Beretta L: Profiling changes in gene expression during differentiation and maturation of monocyte-derived dendritic cells using both oligonucleotide microarrays and proteomics. J Biol Chem 200I, 276:17920-1793I.

38. Shibakura M, Niiya K, Niiya M, Asaumi N, Yoshida C, Nakata Y, Tanimoto M: Induction of CXC and CC chemokines by all- trans retinoic acid in acute promyelocytic leukemia cells. Leuk Res 2005, 29:755-759.

39. Galgani M, de Rosa V, de Simone S, Leonardi A, D'Oro U, Napolitani G, Masci AM, Zappacosta S, Racioppi L: Cyclic AMP modulates the functional plasticity of immature dendritic cells by inhibiting Src-like kinases through protein kinase A mediated signaling. J Biol Chem 2004, 279:32507-325I4.

40. Majewski M, Bose TO, Sillé FC, Pollington AM, Fiebiger E, Boes M: Protein kinase $\mathbf{C}$ delta stimulates antigen presentation by Class II MHC in murine dendritic cells. Int Immunol 2007, 19:719-732.

41. Koski GK, Schwartz GN, Weng DE, Czerniecki BJ, Carter C, Gress RE, Cohen PA: Calcium mobilization in human myeloid cells results in acquisition of individual dendritic cell-like characteristics through discrete signaling pathways. J Immunol 1999, 163:82-92.

42. Rivollier A, Perrin-Cocon L, Luche S, Diemer H, Strub JM, Hanau D, van Dorsselaer A, Lotteau V, Rabourdin-Combe C, Rabilloud T, Servet-Delprat C: High expression of antioxidant proteins in dendritic cells: possible implications in atherosclerosis. Mol Cell Proteomics 2006, 5:726-736.

43. Kim HJ, Barajas B, Chan RC, Nel AE: Glutathione depletion inhibits dendritic cell maturation and delayed-type hypersensitivity: implications for systemic disease and immunosenescence. J Allergy Clin Immunol 2007, I I 9: I 225-I 233.

44. Zeng Z, Xu X, Zhang $Y$, Xing J, Long J, Gu L, Wang X, Sun D, Ka W Yao W, Wen Z, Chien S: Tumor-derived factors impaired motility and immune functions of dendritic cells through derangement of biophysical characteristics and reorganization of cytoskeleton. Cell Motil Cytoskeleton 2007, 64:186-198.

45. Sugihara A, Okamoto $H$, Horio T: Effects of UVB on fascin expression in dendritic cells and Langerhans cells. J Dermatol Sci 2005, 40: 177-185.
46. Li C, Wong WH: Model-based analysis of oligonucleotide arrays: expression index computation and outlier detection. Proc Natl Acad Sci USA 200I, 98:3 I-36.

47. Tibshirani R, Walther G, Hastei $T$ : Estimating the number of clusters in a dataset via the Gap statistic. J Royal Statistical Society B 200I, 63:4II-423.

48. Hartigan JA, Wong MA: "A K-Means Clustering Algorithm". Applied Statistics 1979, 28(I): 100-108.

49. Pereira SR, Faca VM, Gomes GG, Chammas R, Fontes AM, Covas DT, Greene LJ: Changes in the proteomic profile during differentiation and maturation of human monocyte-derived dendritic cells stimulated with granulocyte macrophage colony stimulating factor/interleukin-4 and lipopolysaccharide. Proteomics 2005, 5: I 186-II 98.

50. Shevchenko A, Wilm M, Vorm O, Mann M: Mass spectrometric sequencing of proteins from silver-stained polyacylamide gels. Anal Chem 1996, 68:850-858.

5I. Beavis RC, Chait BT: Matrix-assisted laser desorption ionization mass-spectrometry of proteins. Methods Enzymol 1996, 270:5I9-55I.

52. Staniforth V, Wang SY, Shyur LF, Yang NS: Shikonins, phytocompounds from Lithospermum erythrorhizon, inhibit the transcriptional activation of human tumor necrosis factor alpha promoter in vivo. J Biol Chem 2004, 279:5877-5885.
Publish with Bio Med Central and every scientist can read your work free of charge

"BioMed Central will be the most significant development for disseminating the results of biomedical research in our lifetime. "

Sir Paul Nurse, Cancer Research UK

Your research papers will be:

- available free of charge to the entire biomedical community

- peer reviewed and published immediately upon acceptance

- cited in PubMed and archived on PubMed Central

- yours - you keep the copyright

Submit your manuscript here:

http://www.biomedcentral.com/info/publishing_adv.asp
BiolMedcentral 